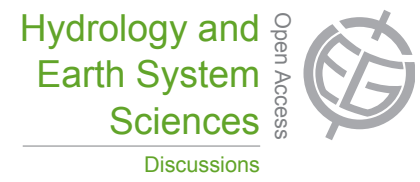

This discussion paper is/has been under review for the journal Hydrology and Earth System Sciences (HESS). Please refer to the corresponding final paper in HESS if available.

\section{A dual-pass data assimilation scheme for estimating surface energy fluxes with FY3A-VIRR land surface temperature}

\section{T. R. $X u^{1}$, S. M. Liu ${ }^{1}$, Z. W. $X u^{1}$, S. Liang ${ }^{2}$, and L. $X u^{1}$}

${ }^{1}$ State Key Laboratory of Remote Sensing Science, Jointly Sponsored by Beijing Normal University and the Institute of Remote Sensing Applications of Chinese Academy of Sciences, Beijing Key Laboratory for Remote Sensing of Environment and Digital Cities, School of Geography, Beijing Normal University, Beijing, 100875, China

${ }^{2}$ Department of Geographical Sciences, University of Maryland, College Park, MD 20742, USA

Received: 26 February 2013 - Accepted: 12 March 2013 - Published: 28 March 2013

Correspondence to: T. R. Xu (xutr@bnu.edu.cn)

Published by Copernicus Publications on behalf of the European Geosciences Union.

\section{HESSD}

10, 3927-3972, 2013

A dual-pass data assimilation scheme

for estimating

surface energy fluxes

T. R. Xu et al.

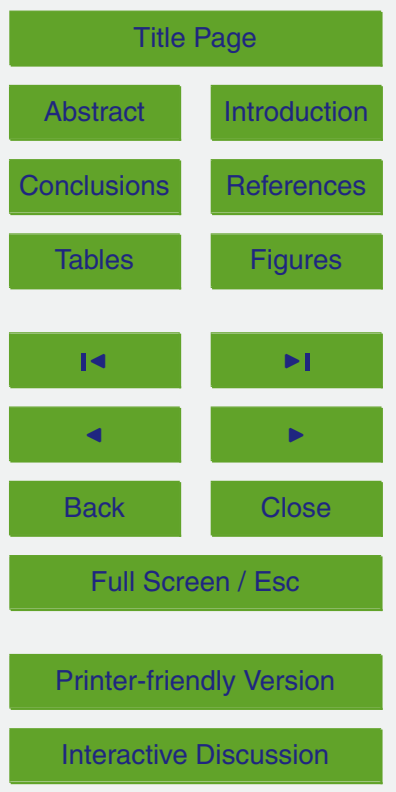




\section{Abstract}

A dual-pass data assimilation scheme is developed to improve predictions of surface energy fluxes. Pass 1 of the dual-pass data assimilation scheme optimizes model vegetation parameters at the weekly temporal scale and pass 2 optimizes soil moisture 5 at the daily temporal scale. Based on the ensemble Kalman filter (EnKF), land surface temperature (LST) data derived from the new generation of Chinese meteorology satellite (FY3A-VIRR) is assimilated into common land model (CoLM) for the first time. Four sites are selected for the data assimilation experiments, namely Arou, BJ, Guantao, and Miyun that include alpine meadow, grass, crop, and orchard land cover types.

The results are compared with data set generated by a multi-scale surface energy flux observation system that includes an automatic weather station (AWS), an eddy covariance (EC) and a large aperture scintillometer (LAS). Results indicate that the CoLM can simulate the diurnal variations of surface energy flux, but usually overestimates sensible heat flux and underestimates latent heat flux and evaporation fraction (EF). With FY3A-VIRR LST data, the dual-pass data assimilation scheme can reduce model uncertainties and improve predictions of surface energy flux. Compared with EC measurements, the average model biases (BIAS) values change from 37.8 to $7.7 \mathrm{~W} \mathrm{~m}^{-2}$ and from -27.6 to $18.8 \mathrm{~W} \mathrm{~m}^{-2}$; the root mean square error (RMSE) values drop from 74.7 to $39.1 \mathrm{~W} \mathrm{~m}^{-2}$ and from 95.1 to $62.7 \mathrm{~W} \mathrm{~m}^{-2}$ for sensible and latent heat fluxes respectively. For evaporation fraction (EF), the average BIAS values change from -0.29 to 0.0 and the average RMSE values drop from 0.38 to 0.12 . To compare the results with LAS-measured sensible heat flux, the source areas are calculated using a footprint model and overlaid with FY3A pixels. The four sites averaged BIAS values drop from 63.7 to $-8.5 \mathrm{~W} \mathrm{~m}^{-2}$ and RMSE values drop from 118.2 to $69.8 \mathrm{~W} \mathrm{~m}^{-2}$. Ultimately, the error sources in surface energy flux predictions are investigated, and the results show that both soil moisture and vegetation parameters caused the big model biases in surface energy flux predictions. With Pass 1 and Pass 2, the dual-pass data assimilation scheme can cut down the surface energy flux prediction biases (BIAS) to nearly zero.
HESSD

10, 3927-3972, 2013

A dual-pass data assimilation scheme for estimating surface energy fluxes

T. R. Xu et al.

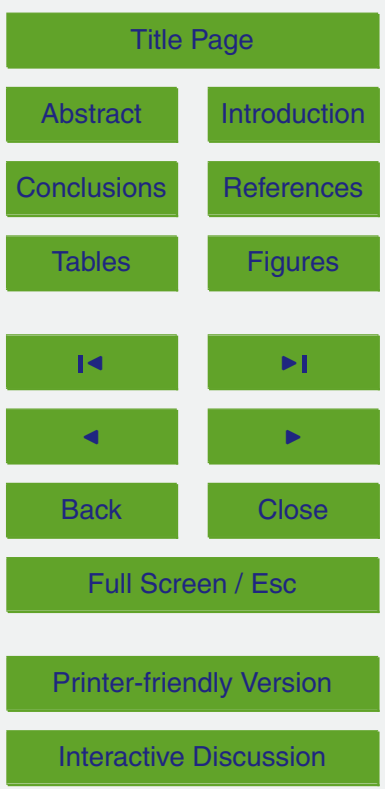




\section{Introduction}

Accurate monitoring surface energy fluxes over land surfaces are necessary for global climate change research, government of ecological environment, as well as agricultural and water resource planning. The magnitude of surface energy fluxes is largely deter5 mined by vegetation parameters, soil moisture and other states of the land surface. The major methods used for estimating surface energy fluxes are field measurements, remote sensing based method, and land surface modeling.

Field measurements of surface energy flux have documented their variability over diurnal, seasonal, and inter-annual time scales (Liu et al., 2011). Some permanent observation networks also have been constructed, such as the First International Satellite Land Surface Climatology Project (ISLSCP) Field Experiment (FIFE) (Kanemasu et al., 1992) and the FLUXNET (Baldocchi et al., 2001). Direct observations such as lysimeter, eddy covariance systems, Bowen ratio methods, and large aperture scintillometer, are necessary for increasing our understanding of water and energy balance at the land surface. However, these measurements are difficult to use for monitoring surface energy fluxes at the regional scale, since they only produce either point or patch-scale data.

Spatially-distributed estimates of surface energy flux can be obtained by remote sensing based method (Bastiaanssen et al., 1998; Su, 2002; Liu et al., 2007). However, these methods are difficult to use to monitor surface energy fluxes continuously, since data derived from satellite are instantaneous and often contaminated by the presence of clouds. Land surface models have been developed rapidly to predict surface energy fluxes on continuous spatial and temporal scales with physical constraints (Dickinson et al., 1986; Sellers et al., 1996; Liou et al., 1999; Dai et al., 2003).

25 Regardless of their specific model structure, all land surface models need observational data to calibrate their parameters and adjust their states. New techniques such as data assimilation, is needed to integrate either field or remotely-sensed observations with models, and in so doing, improve model accuracy by correcting model state
HESSD

10, 3927-3972, 2013

A dual-pass data assimilation scheme for estimating surface energy fluxes

T. R. Xu et al.

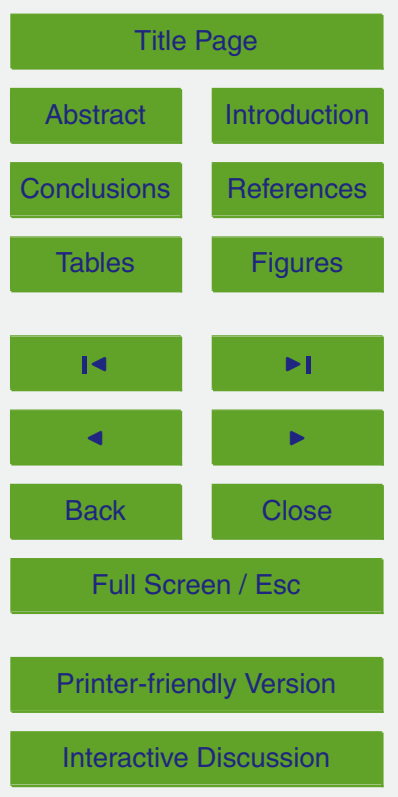


variables and parameters (Liang, 2004; Liang and Qin, 2008). Data assimilation has played an increasingly important role in improving predictions of land surface state variables such as leaf area index (Xiao et al., 2011), soil temperature profile (Huang et al., 2008), soil moisture profile (Margulis et al., 2002), and other related variables such as 5 surface energy fluxes (Xu et al., 2011).

In order to model surface energy fluxes at the land surface, the acquisition of accurate land surface temperatures is very important. Land surface temperature can control the relative humidity at the land surface. For the same magnitude of solar radiation, the lower land surface temperatures results from a wet land surface associated 10 with relatively high latent heat flux and low sensible heat flux. The inaccurate surface energy flux predictions are highly correlated with errors in land surface temperature estimates. Therefore, assimilation of land surface temperatures has become an important way for improving surface energy flux predictions from land surface models. Huang et al. (2008) improved the surface ground heat flux predictions in a land surface 15 model with the assimilation of MODIS land surface temperature products. The surface energy fluxes can also be obtained on the basis of variational techniques and relatively simple models with the assimilation of field measured land surface temperatures (Boni et al., 2001; Caparrini et al., 2004). Bateni and Liang (2012) estimated soil and canopy surface energy fluxes with a dual-source data assimilation scheme. Xu et al. (2011) improved surface energy flux predictions by assimilating remotely-sensed land surface temperatures. Moreover, the surface energy balance algorithm for land (SEBAL) or surface energy balance system (SEBS) can calculate instantaneous surface energy fluxes using meteorology data coupled with remotely-sensed land surface parameters. These estimates can, in turn, be assimilated into land surface models. Schuurmans et al. $(2003,2011)$ showed that the assimilation of remotely-sensed evapotranspiration derived from SEBAL is useful in hydrological model calibration. Pipunic et al. (2008) did experiments with the assimilation of land surface temperature, land surface soil moisture and surface energy fluxes derived from synthetic remote sensing data, and the greatest improvements in the land surface fluxes were found with the assimilation
HESSD

10, 3927-3972, 2013

A dual-pass data assimilation scheme

for estimating

surface energy fluxes

T. R. Xu et al.

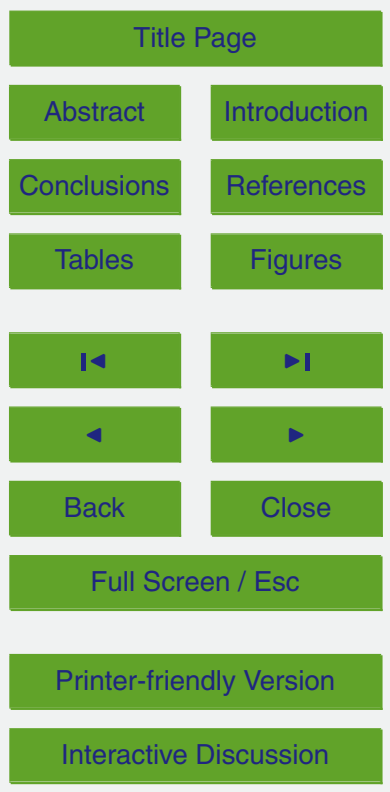


of remotely-sensed surface energy fluxes. However, researchers did not pay much attention to improve surface energy flux predictions using remote sensing land surface temperature.

In land surface model, the sensible and latent heat fluxes are prognostic variables, 5 and they are affected by many factors (e.g. model states and parameters). Thus, new data assimilation strategy should be introduced to estimate surface energy fluxes by optimizing both model states and parameters. The data assimilation strategies which can simultaneously optimize both model states and parameters have been developed to estimate soil moisture profiles (Moradkhani et al., 2005; Qin et al., 2009; Tian et al., 10 2009). Yang et al. (2007) developed an auto-calibration data assimilation scheme to improve soil moisture simulations by optimizing both soil parameters and soil moisture. By assimilating microwave brightness temperatures, the soil parameters are calibrated firstly at the monthly temporal scale and then the soil moisture are updated at the daily temporal scale. Ultimately, they obtained improvements in soil moisture predictions, 15 and they proved that soil moisture is an important land surface variable for energy budget prediction. This study firstly introduced a dual-pass data assimilation scheme to improve surface energy flux predictions by assimilating remotely sensed land surface temperatures into a land surface model. By using the dual-pass data assimilation scheme, the soil moisture profiles and model parameters can be optimized with the separate loops at different temporal scales. Pass 1 of the dual-pass data assimilation scheme optimize model parameters at a long temporal scale, which like a parameter calibration procedure. Pass 2 of the scheme optimizes soil moisture at a short temporal scale.

FY3A is the second generation of Chinese polar-orbiting meteorological satellite 25 launched in the year 2008 (Dong et al., 2009). The main task of FY3A satellite includes providing meteorology parameters for numerical weather prediction, monitoring natural disasters globally, monitoring distributions of ice, snow and ozone globally, etc. The satellite overpass time is approximately 10:30 (local solar time) in its descending mode and 22:30 (local solar time) in its ascending mode. VIRR is one of the 11 sensors

\section{HESSD}

10, 3927-3972, 2013

A dual-pass data assimilation scheme for estimating surface energy fluxes

T. R. Xu et al.

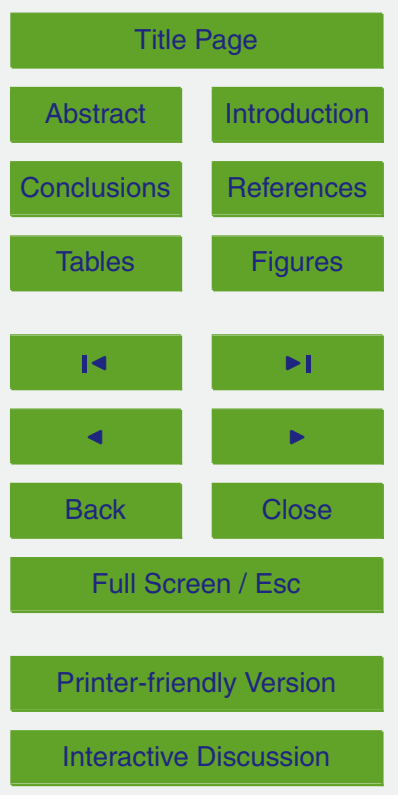


mounted on the FY3A satellite with the nominal spatial resolution about $1 \mathrm{~km} \times 1 \mathrm{~km}$ at the nadir. This study did the first experiment to assimilate remote sensing land surface temperatures (LST) derived from FY3A-VIRR into a land surface model. Four Chinese meteorological sites with different land cover types (alpine meadow, grassland, crop5 land, and orchard) are selected to conduct the data assimilation experiments. Moreover, the results are compared with data generated by a multi-scale surface energy flux observation system that includes an automatic weather station (AWS), an eddy covariance (EC) and a large aperture scintillometer (LAS).

In this paper, Sect. 2 introduces the methodology, including the land surface model 10 (common land model, CoLM), and the data assimilation method (ensemble Kalman filter, EnKF). Section 3 describes the experiment data, including the meteorology data, surface energy flux data from field measurements, and remotely-sensed LST from FY3A-VIRR. Section 4 tests model parameter sensitivities. Section 5 presents the results and discussions, including (i) comparisons of the simulation and assimilation 15 results with eddy covariance (EC) data, (ii) comparisons of the simulation and assimilation results with large aperture scintillometer (LAS) data, and (iii) error sources in surface energy flux predictions. The conclusions are provided in Sect. 6.

\section{Methodology}

A dual-pass data assimilation technique is employed in this study which optimizes 20 model states and parameters independently, and the data assimilation scheme is shown in Fig. 1. The dual-pass data assimilation scheme includes model operator (CoLM), data assimilation algorithm (EnKF), forcing and ancillary data, etc. The two passes of the scheme assimilate remotely-sensed land surface temperatures (LST) derived from FY3A satellite. With the assimilation of FY3A-VIRR LST data, pass 1 is used to optimize model parameters at the weekly temporal scale, and pass 2 is used to optimize soil moisture at the daily temporal scale. For pass 1, the default model parameters are used in CoLM for the first week. At the end of the first week, the model
HESSD

10, 3927-3972, 2013

A dual-pass data assimilation scheme for estimating surface energy fluxes

T. R. Xu et al.

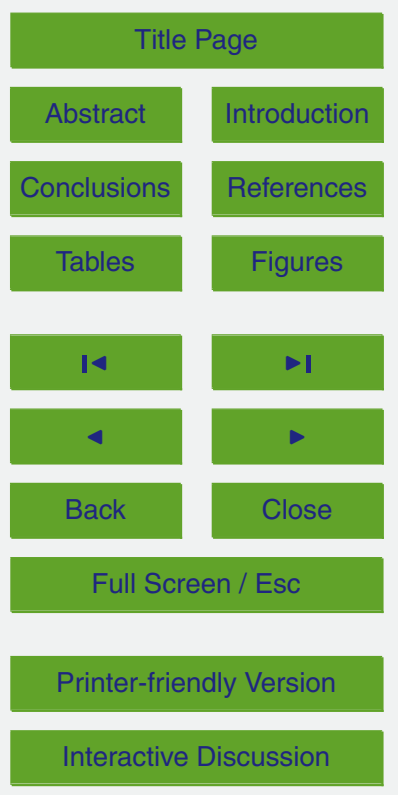


parameter will be updated by minimizing the difference between the predicted LST and FY3A-VIRR LST. In the second week, the optimal model parameter estimates from last week will be used in the whole week, and the parameters will be updated at the end of the week and used in next week. In pass 2, with the optimal model parameter esti5 mates (default model parameters for the first week), the soil moisture will be updated every day (once the FY3A-VIRR LST available) by minimizing the difference between the predicted LST and FY3A-VIRR LST. This section will introduce the model operator and data assimilation algorithm used in the dual-pass data assimilation scheme.

\subsection{Common land model}

Common land model (CoLM) is a state-of-the-art model developed by many groups and validated with extensive field data sites. CoLM can combine many processes such as physical, hydrological, and biological processes together to simulate land states such as soil temperature, soil moisture, surface radiation, and surface energy fluxes (Dai et al., 2001, 2003). CoLM has one vegetation layer and ten unevenly spaced vertical soil layers and up to five snow layers (the number of snow layers could be changed with the total snow depth). A two-big-leaf model was built in 2004 for leaf temperature, photosynthesis, and stomatal conductance that divide the vegetation canopy into sunlit and shaded leaves (Dai et al., 2004).

In CoLM, sensible and latent heat fluxes can be calculated using the land20 atmosphere energy balance equation. For bare ground land surface, the equation is as follows:

$G=R_{\mathrm{n}, \mathrm{g}}-H_{\mathrm{g}}-L E_{\mathrm{g}}$,

where $G$ is soil heat flux at the soil surface $\left(\mathrm{Wm}^{-2}\right) ; R_{\mathrm{n}, \mathrm{g}}$ is the net radiation absorbed by the ground surface $\left(\mathrm{Wm}^{-2}\right) ; H_{\mathrm{g}}$ and $L E_{\mathrm{g}}$ are the sensible and latent heat flux at 25 the soil surface, respectively $\left(\mathrm{Wm}^{-2}\right)$. The soil heat transfer is assumed to obey the following equation:

\section{HESSD}

10, 3927-3972, 2013

A dual-pass data assimilation scheme for estimating surface energy fluxes

T. R. Xu et al.

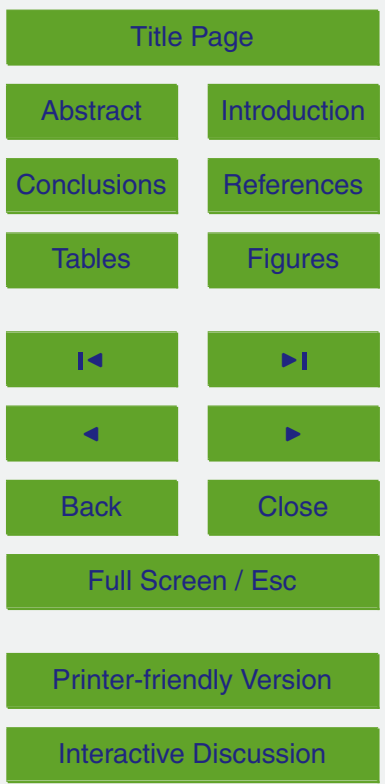


$c \frac{\partial T}{\partial t}=-\frac{\partial F}{\partial z}$

HESSD

where $c$ is the volumetric heat capacity; $T$ is the soil temperature; $t$ means time; $z$ is the vertical coordinate. For vegetated land surface, the leaf temperatures are determined by the energy balance equation for sunlit and shaded fractions of canopy, the sunlit and 5 shaded leaf temperatures can be calculated as follows:

$C_{\mathrm{c}} \frac{\partial T_{\text {csun }}}{\partial t}=0=R_{\mathrm{n}, \mathrm{csun}}-H_{\mathrm{csun}}-L E_{\mathrm{csun}}$,

$C_{\mathrm{c}} \frac{\partial T_{\mathrm{csha}}}{\partial t}=0=R_{\mathrm{n}, \mathrm{csha}}-H_{\mathrm{csha}}-L E_{\mathrm{csha}}$,

where $C_{\mathrm{c}}$ means the canopy heat capacity $\left(\mathrm{Jm}^{-2} \mathrm{~K}^{-1}\right)$ and is assumed to be negli10 gible; $T_{\text {csun }}$ and $T_{\text {csha }}$ means sunlit and shade leaf temperatures $(\mathrm{K}) ; t$ means time; $R_{\mathrm{n}, \mathrm{csun}}$ and $R_{\mathrm{n}, \mathrm{csha}}$ means the net radiation absorbed by the sunlit and shaded canopy $\left(\mathrm{Wm}^{-2}\right) ; H_{\text {csun }}$ and $H_{\text {csha }}$ means sensible heat flux from sunlit and shaded canopy $\left(\mathrm{Wm}^{-2}\right) ; L E_{\text {csun }}$ and $L E_{\text {csha }}$ are the latent heat flux from sunlit and shaded canopy $\left(\mathrm{Wm}^{-2}\right)$.

The total surface energy fluxes from the land surface to atmosphere can be calculated as follows:

$H=H_{\mathrm{g}}+H_{\text {csun }}+H_{\text {csha }}$,

$L E=L E_{\mathrm{g}}+L E_{\text {csun }}+L E_{\text {csha }}$,

20 where $H$ and $L E$ are the sensible and latent heat fluxes from the land surface to atmosphere $\left(\mathrm{Wm}^{-2}\right)$. The details of ground, sunlit and shaded flux calculations can be found in Dai et al. (2003, 2004).

The land surface temperature is a prognostic variable in CoLM, and can be calculated using the following equation:

${ }_{25} T_{\mathrm{S}}=\left(F_{\mathrm{u}} / \varepsilon \sigma\right)^{0.25}$

A dual-pass data assimilation scheme

for estimating

surface energy fluxes

T. R. Xu et al.

Title Page

Abstract

Introduction

Conclusions

References

Tables

Figures

14

$\rightarrow 1$

$\triangleleft$

Back

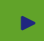

Close

Full Screen / Esc

Printer-friendly Version

Interactive Discussion

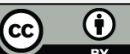


where $T_{\mathrm{s}}$ is the simulated land surface temperature $(\mathrm{K}) ; F_{\mathrm{u}}$ means surface upward longwave radiation emitted from soil and canopy $\left(\mathrm{Wm}^{-2}\right) ; \sigma$ means the Stefan-Boltzmann constant $\left(5.67 \times 10^{-8} \mathrm{Wm}^{-2} \mathrm{~K}^{-4}\right) ; \varepsilon$ means the broadband emissivity (-). This equation can be considered as the observational operator of the dual-pass data assimilation scheme.

In CoLM, soil moisture is important for dividing the net radiation into ground heat flux, sensible heat flux and latent heat flux. The large soil moisture value will lead to large latent heat flux and small sensible heat flux and surface temperature values, and vice versa. The equation for liquid soil water and ice can be expressed as (Dai et al., 2003):

$$
\frac{\partial W_{\text {liq }}}{\partial t}=-\frac{\partial q}{\partial z}-E_{\mathrm{t}}+M_{\mathrm{il}}
$$

where $W_{\text {liq }}$ is the mass of soil water $(\mathrm{kg}), t$ is time, $q$ is the water flow within the soil $\left(\mathrm{kg} \mathrm{m}^{-2} \mathrm{~s}^{-1}\right)$, and $E_{\mathrm{t}}$ is evapotranspiration $\left(\mathrm{kgm}^{-2} \mathrm{~s}^{-1}\right), M_{\mathrm{il}}$ is the mass rate of melting (positive) or freezing (negative) of soil ice.

15 Ten unevenly vertical soil layers are set in CoLM, and the depth of each soil layer is $0.01,0.03,0.06,0.21,0.37,0.62,1.04,1.73,2.86 \mathrm{~m}$ (top to bottom).

The input data of CoLM include ancillary data and forcing data. A variety of ancillary data is needed for modeling, which includes land cover type, soil and vegetation parameters. Land surface types are based on the International Geosphere-Biosphere Programme (IGBP) classification system. Shangguan et al. (2012) developed a conterminous China soil texture (i.e. sand, silt and clay content) dataset with $1 \mathrm{~km} \times 1 \mathrm{~km}$ resolution for land modeling use. Leaf area index (LAI) can characterize vegetation growth conditions and important for surface energy flux estimates, which was derived from the MODIS LAI products, and directly incorporated into CoLM in this study. The other vegetation parameters, such as surface roughness length, are optimized using the dualpass data assimilation scheme. In this study, the forcing data were taken from a continuous series of meteorological data measured by automatic weather stations, with the temporal resolution of half-hour. The data includes wind speed, air temperature, 3935

\section{HESSD}

10, 3927-3972, 2013

A dual-pass data assimilation scheme for estimating surface energy fluxes

T. R. Xu et al.

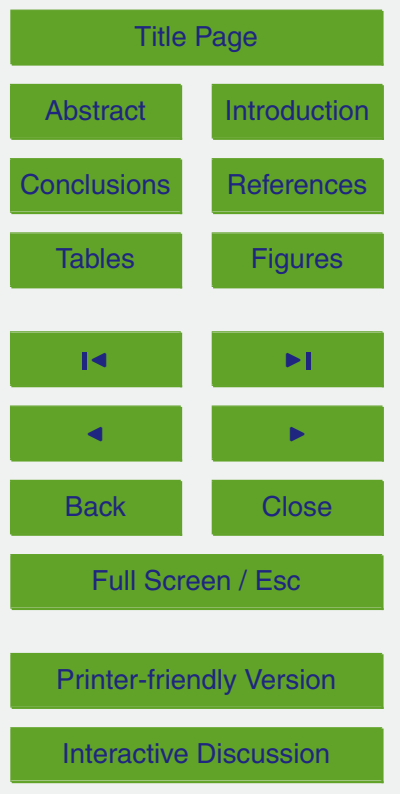


relative humidity, air pressure, precipitation, incoming shortwave radiation, and incoming longwave radiation. The model is run with the same time steps as the measured meteorological data. The field measurements are used for the model state variables initialization such as soil moisture and soil temperature. The spatial scale of CoLM de5 pends on the spatial scale of forcing data and land surface parameters. In this study, ground-measured meteorology data are used as the forcing data which the representativeness is larger than $1 \mathrm{~km}$. The land surface parameters are mainly at the $1 \mathrm{~km}$ spatial scale. Thus, we assume the spatial scale of CoLM is about $1 \mathrm{~km}$.

\subsection{Assimilation method}

10 In this study, the EnKF algorithm is employed as the data assimilation method. For the easy implementation, the EnKF algorithm has been broadly applied in the construction of data assimilation schemes. The EnKF is based on ensemble generations where the approximation of predicted state error covariance matrix is made by spreading an ensemble of model states using states from the previous time step. The key point in the performance of the EnKF is to generate the ensemble of model states or parameters and observations at each update time by introducing noise drawn from a distribution with zero mean and covariance equal to the model states and observation error covariance matrix.

Considering $\boldsymbol{X}=\left[w_{1}, w_{2}, \ldots, w_{10}\right]^{\top}$ as the state vector of the data assimilation 20 scheme, where $w_{1}, w_{2}$, and $w_{10}$ mean the soil moisture of the first layer, second layer and tenth layer. At the first time of the algorithm, the first guest value $X_{0}$ is used to create a series of state vector ensemble members by adding random noises:

$X_{i, 0}=X_{0}+\eta_{i} \quad \eta_{i} \sim N\left(0, \mathbf{B}_{0}\right)$

where $X_{i, 0}$ is the state variables of the $i$-th member at the beginning time; $\eta_{i}$ is the background error vector that conforms to the Gaussian distribution with zero mean and covariance matrix of $\mathbf{B}_{0}$.
HESSD

10, 3927-3972, 2013

A dual-pass data assimilation scheme

for estimating

surface energy fluxes

T. R. Xu et al.

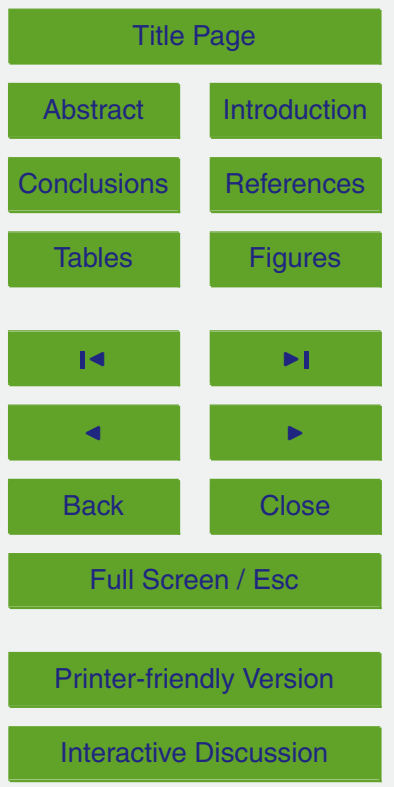


In the forecast step, the each soil moisture ensemble member is predicted according to:

$X_{i, t+1}^{\mathrm{f}}=M\left(X_{i, t}^{\mathrm{f}}, \alpha_{t+1}, \beta_{t+1}\right)+\mu_{i} \quad \mu_{i} \sim N(0, \mathbf{Q})$,

where $X_{i, t}^{\dagger}, X_{i, t+1}^{\dagger}$ represent the forecasted state variables of the $i$-th member at times $5 t$ and $t+1$; the superscript " $f$ " represents the forecasted state variables; $M(\cdot)$ means model operator (CoLM in this study); $\alpha_{t+1}$ and $\beta_{t+1}$ mean forcing data and model parameters at time $t+1 ; \mu_{i}$ is the model error vector, which conforms to Gaussian distribution with zero mean and covariance matrix $\mathbf{Q}(\mathbf{Q}$ : the model error matrix).

When FY3A-VIRR LST is available, the observation operator will predict LST as 10 given by the following equation:

$T_{\mathrm{si}}^{\mathrm{f}}=H\left(X_{i}^{\mathrm{f}}, \alpha, \beta\right)+v_{i} \quad v_{i} \sim N(0, \mathbf{R})$,

where $T_{\mathrm{si}}^{\mathrm{f}}$ is the model predicted land surface temperature of $i$-th member; $H(\cdot)$ means the observation operator that relates model state variables to observations; and $v_{i}$ means the observation error that conforms to Gaussian distributions with zero mean and covariance matrix $\mathbf{R}$ (R: the observation error). The state variable of each member is updated as follows:

$X_{i}^{\mathrm{a}}=X_{i}^{\mathrm{f}}+\mathbf{K}\left(T_{\mathrm{s}}^{\mathrm{o}}-T_{\mathrm{si}}^{\mathrm{f}}\right)$,

$\mathbf{K}=P^{\mathrm{f}} H^{\top}\left(H P^{\mathrm{f}} H^{\top}+\mathbf{R}\right)^{-1}$,

$P^{\mathrm{f}}=\frac{1}{N-1} \sum_{i=1}^{N}\left(X_{i}^{\mathrm{f}}-\bar{X}^{\mathrm{f}}\right)\left(X_{i}^{\mathrm{f}}-\bar{X}^{\mathrm{f}}\right)^{\mathrm{T}}$,

${ }_{20} \quad P^{\mathrm{f}} H^{\top}=\frac{1}{N-1} \sum_{i=1}^{N}\left[X_{i}^{\mathrm{f}}-\bar{X}^{\mathrm{f}}\right]\left[H\left(X_{i}^{\mathrm{f}}\right)-H\left(\bar{X}^{\mathrm{f}}\right)\right]^{\top}$,
HESSD

10, 3927-3972, 2013

A dual-pass data assimilation scheme

for estimating

surface energy fluxes

T. R. Xu et al.

Title Page

Abstract

Introduction

Conclusions

References

Tables

Figures

14

$\rightarrow 1$

$\triangleleft$

Back

Close

Full Screen / Esc

Printer-friendly Version

Interactive Discussion 
and

$H P^{f} H^{\top}=\frac{1}{N-1} \sum_{i=1}^{N}\left[H\left(X_{i}^{f}\right)-H\left(\bar{X}^{f}\right)\right]\left[H\left(X_{i}^{f}\right)-H\left(\bar{X}^{f}\right)\right]^{\top}$,

where $X_{i}^{\mathrm{a}}$ represents the analyzed state variables of the $i$-th member; $\mathbf{K}$ means Kalman gain matrix; $T_{\mathrm{s}}^{\circ}$ means FY3A-VIRR LST observations; $P^{f}$ means the forecasted 5 background covariance matrix; $N$ means the number of ensembles; and $\bar{X}_{i}^{f}$ means the mean of forecasted state vector ensemble members.

By using the dual-pass assimilation technique, EnKF will update model states and parameters separately. Xu et al. (2011) have demonstrated that soil moisture play an important role in predicting surface energy flux in CoLM, and the sensitivity of model parameters is tested in Sect. 4. Thus, the soil moisture and model parameters are updated separately using Eqs. (12)-(16). In pass 1, the state variables $X$ in Eq. (9) include the selected model parameters, while $X$ includes the ten layer model soil moisture in pass 2 .

For applying EnKF technique, the generation of ensemble members of the state vector is necessary; noises should be added to forcing data, model parameters, and model state variables. Since the in-situ meteorology data are used for forcing data, they are not perturbed by adding noises. In this study, the variable ensemble members can be obtained by adding a series of Gaussian distributed noises to the model parameters of pass 1 and model soil moisture of pass 2 . The size of ten layer soil moisture noises 20 are $0.036,0.033,0.033,0.034,0.032,0.030,0.032,0.024,0.024,0.024 \mathrm{~m}^{3} \mathrm{~m}^{-3}$ (from the top to bottom layer), according to $\mathrm{Xu}$ et al. (2011). The size of model parameter noises are set to $10 \%$ of the range of the value (Table 2 ).

Since pass 2 of the dual-pass data assimilation scheme updates soil moisture when the FY3A-VIRR LST data are available, the Eqs. (12)-(16) can be used directly. For pass 1, the analyzed model parameters are calculated when the FY3A-VIRR LST data

A dual-pass data assimilation scheme for estimating surface energy fluxes

T. R. Xu et al.

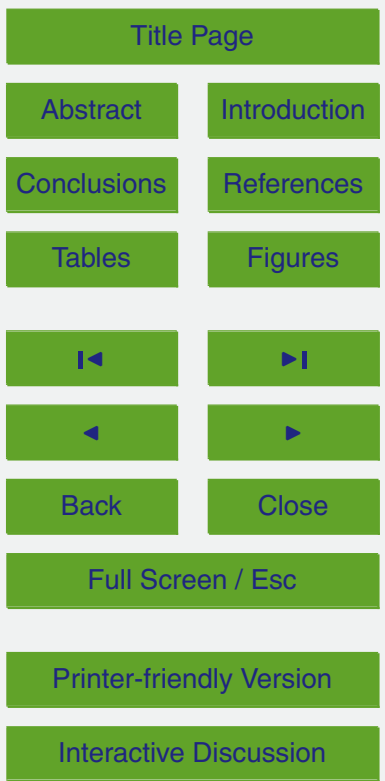


are available, but not updated. At the end of the week, the calculated model parameter analysis are averaged and updated as follows:

$\overline{\beta_{i}^{\mathrm{a}}}=\frac{1}{D} \sum_{k=1}^{D}\left(\beta_{i, t}^{\mathrm{a}}\right)$,

where $\overline{\beta_{i}^{a}}$ represents the averaged model parameter analysis of the $i$-th member; $\beta_{i, t}^{\mathrm{a}}$ 5 means the model parameter analysis of the $i$-th member at the time $t$ in one week; $D$ means the number of FY3A-VIRR LST observations in one week. The averaged model parameter analysis is transferred to pass 2 of the data assimilation scheme.

\section{Experiment data}

\subsection{Site description}

10 Four observation sites are selected for the data assimilation experiments in the People's Republic of China (PRC) in 2010. Arou site is an alpine meadow site covered with dense grass, located in Qinghai province; BJ site is a grassland site covered with sparsely distributed short grass during the rain season, located in Tibet Plateau; Guantao site is a cropland, located in Hebei province; Miyun site is located in the northern 5 mountain area of the Beijing city, with a surface mainly covered with orchard and maize. At each site, an automatic weather station (AWS) and a multi-scale surface energy flux observation system consisting of eddy covariance (EC), large aperture scintillometer (LAS) are set up to acquire surface energy fluxes at two spatial scales simultaneously. The AWS can provide forcing data and auxiliary data model needed. EC measured sensible and latent heat flux and LAS measured sensible heat flux are used to validate the dual-pass data assimilation scheme. In this type of observation system, the LAS system generally covers more than one FY3A-VIRR pixels (1 $\mathrm{km}$ resolution) with an ellipsoid shape footprint. EC and AWS are located beside the center of LAS optical 3939
HESSD

10, 3927-3972, 2013

A dual-pass data assimilation scheme for estimating surface energy fluxes

T. R. Xu et al.

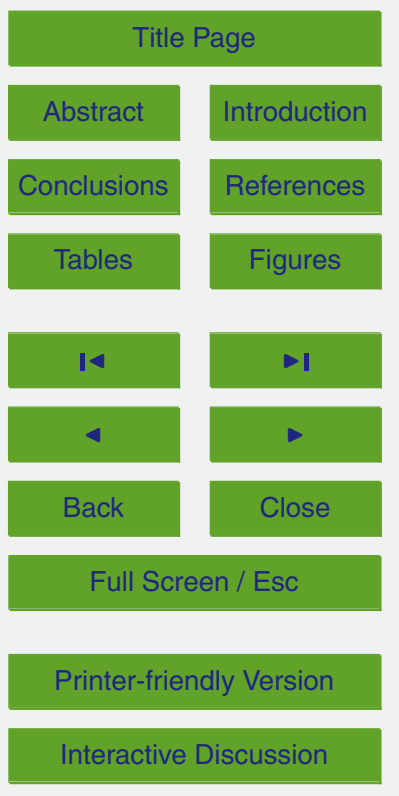


path. Table 1 summarizes the instruments and surface characteristics of the experiment sites.

All of the above observed data of AWS, EC, and LAS were collected in half-hour time step. The processing method of these data can be found in Liu et al. $(2011,2013)$.

5 Generally, the EC measured surface energy fluxes surfer from an energy-imbalance problem. To indicate the quality of EC data, energy balance ratio (EBR, EBR $=$ (sensible heat flux + latent heat flux)/(net radiation - surface soil heat flux)) is calculated to assess the energy-imbalance of each site. The surface soil heat flux is calculated using multi-layer soil temperature and soil moisture observations that proposed by Yang and 10 Wang (2008). Since soil moisture was only measured at 4 and $20 \mathrm{~cm}$ at BJ site and Yang and Wang (2008) needs multi-layer observations to calculate the soil heat flux, the soil heat flux is not calculated and neglected at this site. The EBRs at the four sites are lower than 1 (0.79, 0.83, 0.91, and 0.80 for Arou, BJ, Guantao and Miyun sites) which indicates the energy-imbalance problem of the EC derived surface energy flux.

15 The LAS system consists of a transmitter and a receiver installed on a pair of towers approximately 500-5000 $\mathrm{m}$ apart, which can measure the average value of sensible heat flux along the optical path of the instrument. Generally, the source area of LAS measurements cover more than one FY3A-VIRR pixels, and need to be calculated using a footprint model. The LAS footprint is calculated follows Liu et al. $(2011,2013)$ :

$20 f_{\mathrm{LAS}}\left(x, y, z_{\text {eff }}\right)=\int_{x_{2}}^{x_{1}} W\left(x^{\prime}\right) f\left(x^{\prime}-x, y^{\prime}-y, z_{\text {eff }}\right) \mathrm{d} x^{\prime}$

where $W\left(x^{\prime}\right)$ is the path-weighting function of the LAS, $x_{1}, x_{2}$ are the locations of the LAS transmitter and receiver; $x^{\prime}, y^{\prime}$ are the points along the optical length of the LAS; $x$, $y$ are the coordinates upwind of each point $\left(x^{\prime}, y^{\prime}\right)$; and $z_{\text {eff }}$ is the effective measurement height of LAS. Monthly LAS footprints are used in this study, determined by averaging 25 every half-hourly footprint when the sensible heat fluxes were larger than zero, and footprint values ranging from time period of 22:00 to 06:00 are also excluded.

A dual-pass data assimilation scheme for estimating surface energy fluxes

T. R. Xu et al.

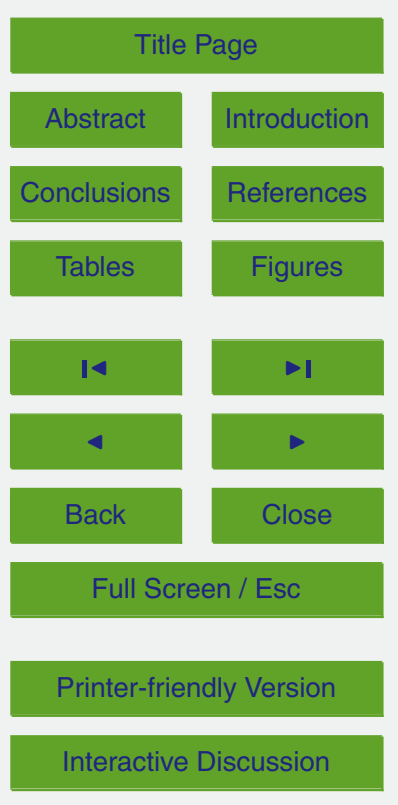

Interactive Discussion

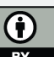




\subsection{FY3A-VIRR Land Surface Temperature (LST)}

Land surface temperature (LST) can be retrieved by using the FY3A visible and infrared radiometer (VIRR) instrument, and the products can be downloaded from the website at http://satellite.cma.gov.cn/PortalSite/Ord/Satellite.aspx. The VIRR is a multi-channel 5 instrument designed for comprehensive detection of earth environment. The VIRR instrument has 10 channels ranged from 0.58 to $12.5 \mu \mathrm{m}$. The 4 th $(10.3 \sim 11.3 \mu \mathrm{m})$ and 5th $(11.5 \sim 2.5 \mu \mathrm{m})$ channel are infrared channels with little water vapor absorption, and they have a nominal spatial resolution of $1 \mathrm{~km} \times 1 \mathrm{~km}$ at the nadir. With these two infrared channels, land surface temperature is obtained based on a local split window

$T_{\mathrm{s}}=A_{0}+P \cdot\left(T_{4}+T_{5}\right) / 2+M \cdot\left(T_{4}-T_{5}\right) / 2$,

where $T_{\mathrm{s}}$ is the FY3A-VIRR LST (K), $A_{0}$ is a constant, $T_{4}$ and $T_{5}$ mean the brightness temperature of the 4th and 5th channel $(\mathrm{K}), P$ and $M$ mean the function of land surface emissivity which can be regressed from the simulated data. Yang and Yang (2006) recalculated the parameters in this algorithm based on the spectral response function of the FY3A-VIRR sensor. The FY3A-VIRR LST products can provide LST and emissivity of each pixel, and the data are stored in the hierarchical data format (HDF), which is a sinusoidal projection with a spatial resolution of $1 \mathrm{~km}$ (Yang and Dong, 2011).

LST derived from FY3A-VIRR need to be validated using in-situ measurements. The ground-measured surface temperatures can be calculated using the upward longwave radiation at land surfaces, land surface emissivity, and downward longwave radiation according to the thermal radiative transfer theory (Liang, 2004).

$T_{\mathrm{s}}=\left\{\left[F_{\mathrm{u}}-(1-\varepsilon) F_{\mathrm{d}}\right] / \varepsilon \sigma\right\}^{0.25}$,

where $T_{\mathrm{s}}$ is land surface temperature $(\mathrm{K}) ; F_{\mathrm{u}}$ is surface upward longwave radia25 tion $\left(\mathrm{Wm}^{-2}\right) ; F_{\mathrm{d}}$ is surface downward longwave radiation $\left(\mathrm{Wm}^{-2}\right) ; \sigma$ is the StefanBoltzmann constant $\left(5.67 \times 10^{-8} \mathrm{Wm}^{-2} \mathrm{~K}^{-4}\right) ; \varepsilon$ is the broadband emissivity (-), which 3941
HESSD

10, 3927-3972, 2013

A dual-pass data assimilation scheme

for estimating

surface energy fluxes

T. R. Xu et al.

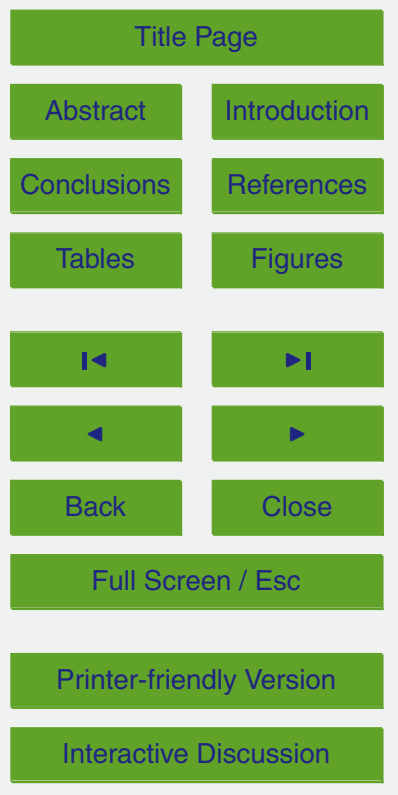

Interactive Discussion 
is 0.987 for grasslands and croplands, and 0.993 for orchard according to Wang et al. (2008).

The FY3A-VIRR LST data are compared with ground measurements (Fig. 2). As shown in Fig. 2, the FY3A-VIRR LST and ground measurements follows the same 5 trend - the correlation coefficients $(R)$ are $0.64,0.77,0.81$, and 0.85 at the AR, BJ, Guantao, and Miyun site, respectively. The FY3A-VIRR LST data are higher than field measurements at Arou site and lower at the other three sites. The root mean square error (RMSE) values between FY3A-VIRR LST data and field measurements are 3.8, $5.0,3.5$, and $3.7 \mathrm{~K}$ at Arou, BJ, Guantao, and Miyun site that are used as the ob10 servational errors in the dual-pass data assimilation scheme. The deviations between FY3A-VIRR LST data and the ground measurements are determined by many factors. The terrain effect can affect the accuracy of FY3A-VIRR LST retrievals. The mismatch of spatial and temporal scales between FY3A-VIRR and field-measured LST can also cause these biases. The remote sensing data such as FY3A-VIRR LST is an instantaneous value, while the ground measurement is a mean value of about $30 \mathrm{~min}$. The spatial resolution of FY3A-VIRR is approximately $1 \mathrm{~km} \times 1 \mathrm{~km}$, while the footprint of ground measurements is an approximately dozens of square meters determined by mount level of the radiometer.

\section{Model parameter sensitivity analysis}

20 In order to determine the parameters which should be optimized afterwards, sensitivity analysis is applied to determine the non-influential factors. Extended Fourier Amplitude Sensitivity Test (EFAST) (Saltelli and Bolado, 1999), as a kind of quantitative global sensitivity analysis methods, is used here to rank model parameters and identify factors which could be considered to be optimized in CoLM. EFAST measures first-order sensitivity index and total effect index to represent the main contribution and the total contribution of each input factor to the variance of the outputs. EFAST is widely applied in crop models (Confalonieri et al., 2010; Drouet et al., 2011), ecological models

A dual-pass data assimilation scheme for estimating surface energy fluxes

T. R. Xu et al.

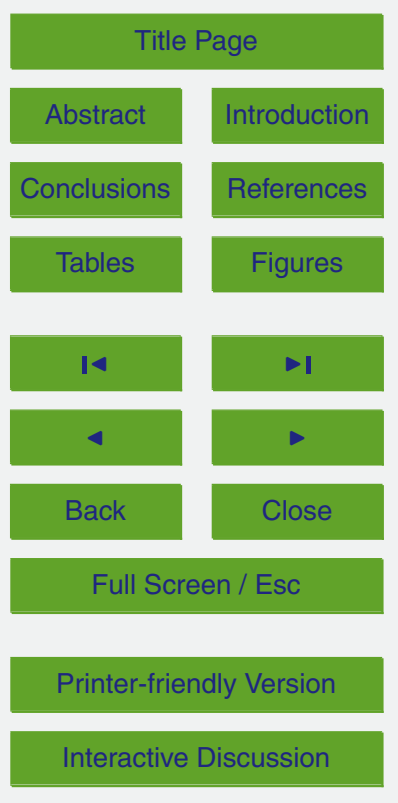


(Crosetto and Tarantola, 2001; Miao et al., 2011) and hydrological models (Crosetto and Tarantola, 2000; Reusser et al., 2011).

Compared with local sensitivity analysis, the global sensitivity analysis has two advantages: (1) parameters are explored within the entire interval; (2) the variation of

5 output is induced by factors globally which means the sensitivity of this factor includes the sole parameter effects as well as the interaction between parameters (Saltelli et al., 2000). For a complex non-linear model like CoLM, it's better to use global sensitivity analysis to do sensitivity analysis for model output. The computation steps of EFAST are as follows:

10 A search-curve with random term to generate random samples for every parameter (Saltelli et al., 2000)

$x_{i}(s)=G_{i}\left(\sin \omega_{i} s\right)=\frac{1}{2}+\frac{1}{\pi} \arcsin \left(\sin \left(\omega_{i} s+\phi_{i}\right)\right)$

where $s$ is an independent variable between $-\pi / 2$ and $\pi / 2, \omega_{i}$ is the frequencies of the interested parameter, $\varphi_{i}$ is a random phase-shift parameter taking values in $[0,2 \pi)$, so the starting point of search-curve can be anywhere within the space of parameters.

By calculating the Fourier spectrum of model output, we can get the Fourier amplitude which represents the contribution to the variance of model output. According to decomposition of variance (Sobol, 1993), the total variance of model output is

$V(Y)=\sum_{i} V_{i}+\sum_{i} \sum_{j>i} V_{i j}+\ldots+V_{12 \ldots k}$,

where $V(Y)$ means the variance of $Y$; and $Y$ is the model output. Based on decomposition of variance, first-order sensitivity index is given by

$S_{i}=V_{i} / V$

HESSD

10, 3927-3972, 2013

A dual-pass data assimilation scheme

for estimating

surface energy fluxes

T. R. Xu et al.

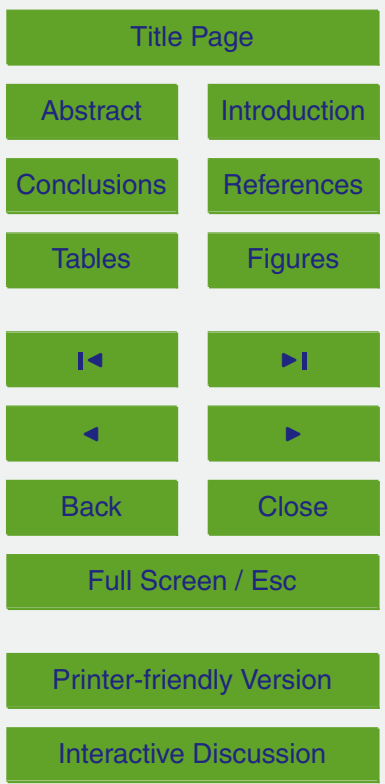


where $S_{i}$ is called first-order sensitivity index, the subscript $i$ indicates that $S_{i}$ is the sensitivity index of parameter $x_{i}$. The first-order sensitivity index represents the main contribution of the $i$-th parameter. The total sensitivity index can be obtained as follows,

$S_{5} \quad S_{\mathrm{Ti}}=1-V_{\sim i} / V$

where $S_{\mathrm{Ti}}$ means the total sensitivity index for the $i$-th parameter and measures the sum of all contributions related to parameter $x_{i}, V_{\sim i}$ means the sum of all variance terms of model output which is not include the variance calculated by parameter $x_{i}$.

The parameters used to calculate surface energy fluxes and their range of value is 10 listed in Table 2. Since it is hard to define the type of probability distribution function (PDF) and different types of PDF would not lead to considerable difference in the result of sensitivity analysis (Rodriguez-Camino and Avissar, 1998), the PDF of parameters is defined as uniform probability distribution. The range of value is set to $90 \% \sim 110 \%$ of parameter range in Table 2.

15 The sensitivity analysis tests are conducted at the four experiment sites. The results at the four sites are similar and averaged in Table 3. According to sensitivity analysis of 10 parameters for sensible, latent heat fluxes and surface temperature, the five most important parameters are surface roughness length $(\mathrm{zOm})$, Quantum efficiency at $25^{\circ} \mathrm{C}$ (effcon), Maximum rate of carboxylation at $25^{\circ} \mathrm{C}$ (vmax25), conductancephotosynthesis slope parameter (gradm), and conductance-photosynthesis intercept (binter) (Table 3). Apart from four parameters, other factors have no obvious effects on output variables so they can be set to default value. The five most important parameters are selected and optimized using EnKF in this study. Among the four important model parameters, Maximum rate of carboxylation at $25^{\circ} \mathrm{C}$ (vmax25), Quantum efficiency at $25^{\circ} \mathrm{C}$ (effcon), conductance-photosynthesis slope parameter (gradm), and conductance-photosynthesis intercept (binter) are factors related to canopy photosynthesis or stomata resistance function.

\section{HESSD}

10, 3927-3972, 2013

A dual-pass data assimilation scheme for estimating surface energy fluxes

T. R. Xu et al.

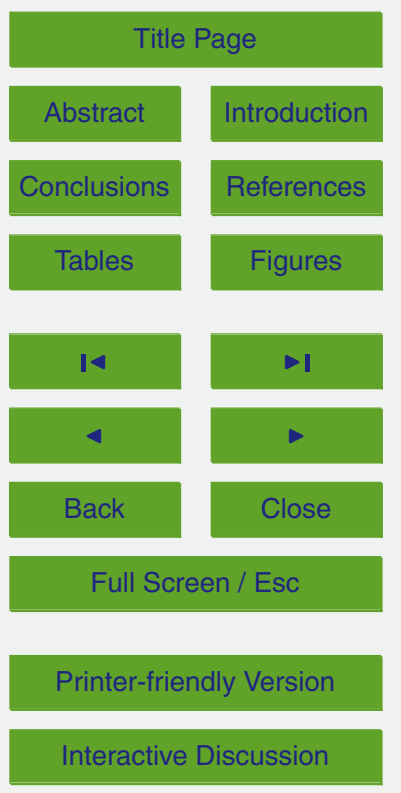




\section{Results and discussions}

In this study, the FY3A-VIRR LST is assimilated into CoLM with the developed dualpass data assimilation scheme, and results are compared with the multi-scale surface energy flux observations at the four experiment sites in this section. The data assimila5 tion scheme is conducted in the vegetation growing season, and the data of day of year from 121 to 273 (from May to September) in 2010 is selected for the tests and validations. Statistics of model biases (BIAS = model predictions - observations), root mean square error (RMSE) and correlation $(R)$ are selected to assess the performance of the data assimilation scheme. In Sect. 5.1, the results are validated using EC-derived 列 sensible heat flux. In Sect. 5.3, the retrieved soil moisture and model parameters are shown and the error sources in surface energy flux predictions are analyzed.

\subsection{Comparisons of the simulation and assimilation results with EC data}

In this section, the ground-measured land surface temperature and EC derived sensible 15 and latent heat flux is used to validate the results, which are shown in Figs. 3 and 4 and Table 4.

Generally, the diurnal variations trend of land surface temperature and surface energy flux can be predicted correctly by the CoLM (Fig. 3). However, the land surface temperatures and the sensible heat flux are overestimated and the latent heat flux is underestimated with the model. The obvious errors in surface temperature and surface energy flux modeling are corrected with the assimilation of FY3A-VIRR LST data. The curves portrayed by the dual-pass data assimilation scheme are generally closer to the EC measurements than the model predictions. From Fig. 3, the model simulated latent heat flux reach the peak relative early (about 10 a.m.), and sometimes nearly

FY3A-VIRR LST, the model can simulate the diurnal variations of latent heat flux like observations. From Eqs. (5) and (6), the surface energy fluxes can be produced by the 
vegetation canopy and ground. Take evapotranspiration for example, the errors of transpiration from canopy and the errors of evaporation from ground can be caused by the vegetation parameters and soil moisture. In this study, the MODIS LAI products are incorporated into the model directly, and the vegetation parameters are optimized at the 5 weekly temporal scale with pass 1 of the dual-pass data assimilation scheme. At the daily temporal scale, the soil moisture is optimized with pass 2 of the dual-pass data assimilation scheme. With optimized vegetation parameters and soil moisture, CoLM can produce more exact latent heat flux.

Daily averaged evaporation fraction (EF, ratio between latent heat flux and available 10 energy) can be used to describe the splitting of available energy into sensible and
latent heat flux. In CoLM, EF is important for energy balance and it describes the magnitude of available energy for evapotranspiration. Thus, the simulation and assimilation results are also assessed with EC-derived EF. In this study, the daily averaged EF is calculated using EF = latent heat flux/(latent heat flux + sensible heat flux). Figure 4 5 shows the comparisons of simulation and assimilation results with EC derived EF at the four experiment sites from day of year 121 to 273 (from May to September), 2010. From Fig. 4, the CoLM usually underestimates the EF which means the model splits relative less available energy for evapotranspiration. Precipitation data is also drawn in Fig. 4, the model simulated EF is increased quickly after precipitation happens which indicates that soil moisture is important for predictions of surface energy fluxes. However, the EF drop down after a short period of precipitation, and EF is increased and closer to observations with the assimilation of FY3A-VIRR LST data.

Table 4 summarizes the BIAS, RMSE and $R$ values of the model simulation and assimilation results compared with the EC-derived surface energy fluxes at the four sites. From this table, the developed dual-pass data assimilation scheme can improve the predictions of surface energy flux and surface temperature. For sensible and latent heat fluxes, the model biases and RMSE drop down (the average BIAS values of the four sites change from 37.8 to $7.7 \mathrm{Wm}^{-2}$ and from -27.6 to $18.8 \mathrm{Wm}^{-2}$; the average RMSE values drop from 74.7 to $39.1 \mathrm{Wm}^{-2}$ and from 95.1 to $62.7 \mathrm{Wm}^{-2}$, and the
HESSD

10, 3927-3972, 2013

A dual-pass data assimilation scheme

for estimating

surface energy fluxes

T. R. Xu et al.

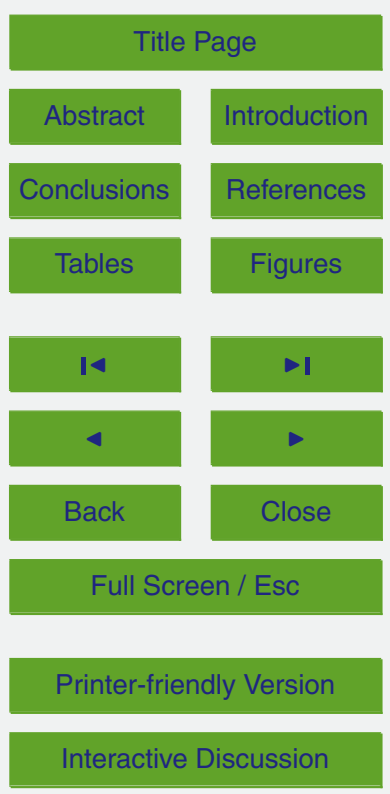


RMSE values drop 47.6 and $34.1 \%$ ) and the correlation between model and observations are increased (the average $R$ values increase from 0.76 to 0.81 and from 0.54 to 0.86 ). At Arou site, the dual-pass data assimilation scheme improve surface energy flux predictions significantly, and the RMSE values drop from 97.9 to $36.5 \mathrm{Wm}^{-2}$ and 5 from 116.8 to $53.9 \mathrm{Wm}^{-2}$ (the RMSE drop 62.7 and $53.9 \%$ ), and the $\mathrm{R}$ values increase from 0.75 to 0.84 and from 0.53 to 0.93 for sensible and latent heat fluxes, respectively. For the evaporation fraction (EF), the average BIAS values of assimilation EF results drop from -0.29 to 0.0 ; the average RMSE values drop from 0.38 to 0.12 ; the average $R$ values increase from 0.31 to 0.57 . All of the statistics conveyed a message that the 10 dual-pass data assimilation scheme reduced the model uncertainties and improved the prediction abilities of the model.

\subsection{Comparisons of the simulation and assimilation results with LAS data}

Depending on the spatial representativeness of ground-measured meteorology data and surface parameters, the spatial scale of the CoLM is about $1 \mathrm{~km}$, while the repre5 sentative of EC is usually within $1 \mathrm{~km}$. The different spatial scales of them may cause problems in the validation. However, the LAS instrument can measure sensible heat flux at the larger scale than EC system. Thus, LAS measured sensible heat flux is compared with dual-pass data assimilation results in this section.

In order to demonstrate the accuracy of the LAS data, the sensible heat flux derived 20 from LAS system is compared with data from EC system (Fig. 5). The LAS and EC sensible heat flux values that larger than $50 \mathrm{Wm}^{-2}$ are used for this comparison. From Fig. 5, the sensible heat flux from LAS system has the same trend with that from EC system, and sensible heat flux from LAS is little larger than that from EC. The correlation between them is $0.87,0.78,0.74,0.44$ at the Arou, BJ, Guantao and Miyun

site, respectively. The difference between the sensible heat flux measured by EC and LAS system mainly caused by the energy imbalance of the $\mathrm{EC}$, the heterogeneity of the underlying surfaces, and the differences between the source areas of the EC and LAS measurements (Liu et al., 2011). Miyun site is located in a mountain area with 3947

\section{HESSD}

10, 3927-3972, 2013

A dual-pass data assimilation scheme

for estimating

surface energy fluxes

T. R. Xu et al.

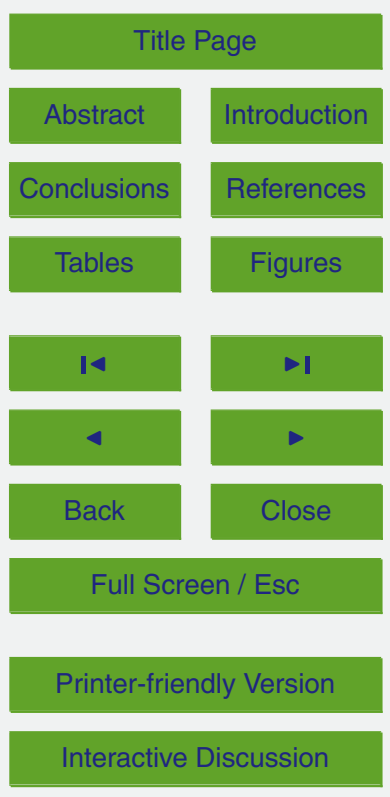


complex land surface characteristics that may lead to big differences between LAS and EC-derived sensible heat flux.

Since the source area of LAS measurements can cover more than one FY3A-VIRR pixel, the weight of each covered pixel should be determined for the comparison. The 5 source areas are calculated using a footprint model (Eq. 18) and overlaid with FY3AVIRR pixel at the experiment sites shown in Fig. 6. From this figure, The LAS source area did not show obvious variation, and extend from the transmitter to the receiver point with the main contributing source areas of approximately half pixel width and 2 or 3 pixel length. Obviously, the weight of each pixel covered by LAS source areas can be 10 determined as (Jia et al., 2012):

$H_{\text {average }}=\sum_{i=1}^{n}\left(w_{i} \times H_{i}\right)$

where $H_{\text {average }}$ is the model results with the same spatial representativeness as the LAS observation, $w_{i}$ is the relative weight of each pixel, $H_{i}$ is the model results of each remote sensing pixel, and $n$ is the number of pixels within the source area.

The comparison results at the four experiment sites are shown in Fig. 7. From this figure, the sensible heat flux with the assimilation of FY3A-VIRR LST is closer to LAS observations than model simulation, and the scatters with the assimilation of FY3AVIRR LST are closer to $1: 1$ line. The larger $R$ indicates the assimilation results have higher correlation with LAS measurements than model simulation. The four sites aver20 aged BIAS values drop from 63.7 to $-8.5 \mathrm{Wm}^{-2}$, and RMSE values drop from 118.2 to $69.8 \mathrm{Wm}^{-2}$ (the RMSE values drop $40.9 \%$ ). The RMSE values of sensible heat flux drop from 162.6 to $51.3 \mathrm{Wm}^{-2}$, from 129.2 to $80.9 \mathrm{Wm}^{-2}$, and from 96.0 to $48.5 \mathrm{Wm}^{-2}$ (the RMSE values drop 68.5, 37.4, and 49.5\%) for Arou, BJ, and Guantao site, respectively. At Miyun site, the sensible heat flux from LAS has a big difference with data from EC (Fig. 5), and the $R$ value of data assimilation result increases from 0.30 to 0.48 with the LAS validation, while the BIAS value change from -17.3 to $-79.5 \mathrm{Wm}^{-2}$ and RMSE value increases from 84.8 to $98.4 \mathrm{Wm}^{-2}$.

A dual-pass data assimilation scheme for estimating surface energy fluxes

T. R. Xu et al.

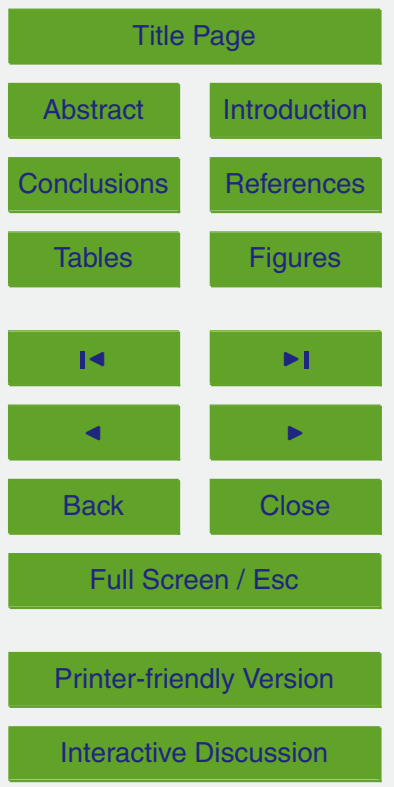




\subsection{Error sources in surface energy flux predictions}

Since soil moisture plays an important role in the terrestrial water cycle, and the vegetation parameters play a significant role in water and energy movement among land surface, canopy and atmosphere. The soil moisture and vegetation parameters are 5 selected and optimized with the dual-pass data assimilation scheme to improve the predictions of surface energy flux. This section first presents the retrieved soil moisture and vegetation parameters from the dual-pass data assimilation scheme. Then, the error sources in surface energy flux predictions are investigated and analyzed.

Figure 8 shows soil moisture retrievals at the depth of $0.05,0.1,0.2,0.4,0.6$, and $101.0 \mathrm{~m}$ of Miyun site (Orchard) from day of year 121 to 273,2010 . Totally, the retrieved soil moisture with data assimilation is closer to observations than model simulation at some depth, but not all depth. As is shown in Fig. 8, at the depth of 0.05, 0.1, 0.2, and $0.6 \mathrm{~m}$, the assimilation results are closer to the observations than model predictions during this time period, and the RMSE values of soil moisture retrievals drop down through the assimilation of FY3A-VIRR LST data. At the depth of 0.4 and $1.0 \mathrm{~m}$, the simulation results are closer to observations than assimilation results. From Fig. 8, we can see that the soil moisture assimilation results are updated as the FY3A-VIRR LST is assimilated, and the soil moisture assimilation results fluctuate more frequently than model simulation and observation. However, fluctuation frequency of the soil moisture simulation results is more like the observation. Thus, the correlation values of soil moisture model simulations are higher than data assimilation. The soil moisture data assimilation results at the other sites perform similar with Miyun site, and the results are not shown.

Figure 9 shows the seasonal variations of the retrieved five vegetation parameters at the Miyun site (Orchard) from day of year 121 to 273, 2010. From Fig. 9, the parameters are retrieved at the weekly temporal scales with the dual-pass data assimilation scheme, which indicates the vegetation parameters are updated once per week. With the assimilation of FY3A-VIRR LST, the parameter uncertainties are within a relative
HESSD

10, 3927-3972, 2013

A dual-pass data assimilation scheme for estimating surface energy fluxes

T. R. Xu et al.

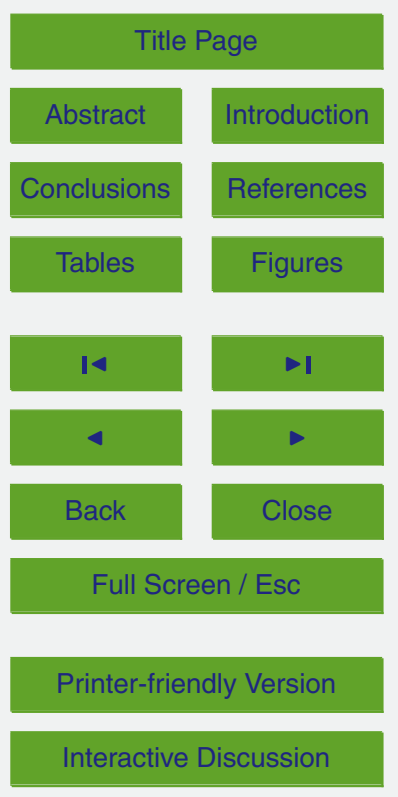


stable range (the error bar of Fig. 9). After a time period of assimilation with FY3A-VIRR LST data, the parameters tend to be a stable value. Surface roughness length $(\mathrm{zO} \mathrm{m})$ and conductance-photosynthesis intercept (binter) increase to a high value; Quantum efficiency at $25^{\circ} \mathrm{C}$ (effcon), and conductance-photosynthesis slope parameter (gradm) 5 decreases to a low value; Maximum rate of carboxylation at $25^{\circ} \mathrm{C}$ (vmax25) does not change much compared with the initial value.

The errors in surface energy flux predictions are mainly model biases (Figs. 3 and 4) and the dual-pass data assimilation can cut down model biases significantly (Table 4). Figure 10 presented the abilities of pass 1 and pass 2 of the dual-pass data assimila10 tion scheme in reducing the biases at the four sites from May to September 2010. The evaporation fraction (EF) BIAS between the predicted and EC observations are shown in Fig. 10. From this figure, there is a big model bias between CoLM simulations and observations, and the dual-pass data assimilation scheme can cut down the biases (BIAS) to nearly zero. Both Pass 1 (optimizing vegetation parameter) and Pass 2 of the 15 scheme (optimizing soil moisture) play important role in surface energy flux predictions. Pass 2 of the scheme (optimizing soil moisture) performs better than Pass 1 (optimizing vegetation parameter) and can cut down the BIAS significantly, especially at Arou and BJ sites (grassland), which means soil moisture plays an important role in improving predictions of surface energy flux. Pass 1 performed better at Guantao (Cropland) and Miyun (Orchard) sites than at Arou and BJ sites (Grassland). Thus, both soil moisture and vegetation parameters caused the big model biases in surface energy flux predictions, soil moisture is the most important and vegetation parameters is the second important factors. With Pass 1 and Pass 2, the dual-pass data assimilation scheme can cut down most of the surface energy flux prediction biases.

\section{Conclusions}

In this study, a dual-pass data assimilation scheme was constructed to estimate the surface energy fluxes by the independent optimization of soil moisture and vegetation

\section{HESSD}

10, 3927-3972, 2013

A dual-pass data assimilation scheme for estimating surface energy fluxes

T. R. Xu et al.

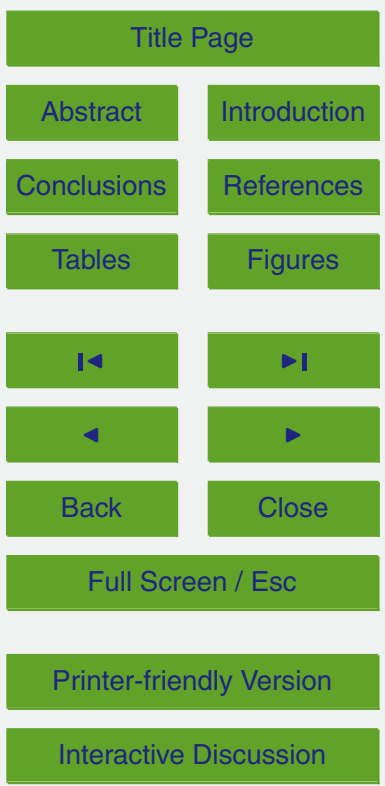


parameters. Pass 1 of the data assimilation scheme optimized vegetation parameters at weekly temporal scale, and pass 2 optimized soil moisture at daily temporal scale. Land surface temperature data from the new generation of Chinese meteorology satellite FY3A-VIRR was assimilated into CoLM for the first time based on the EnKF algo5 rithm. The results were validated using multi-scale surface energy flux observations (derived from EC and LAS) at four sites. Ultimately, the soil moisture and vegetation parameters were retrieved, and the error sources in surface energy flux predictions were analyzed.

Through the comparisons with EC-derived sensible and latent heat flux, the assim10 ilation curves match well with observations (Fig. 3). The dual-pass data assimilation scheme reduced the model uncertainties and improved the prediction abilities of the model. The BIAS and RMSE drop down (the average BIAS values of the four sites change from 37.8 to $7.7 \mathrm{Wm}^{-2}$ and from -27.6 to $18.8 \mathrm{Wm}^{-2}$; the average RMSE values drop from 74.7 to $39.1 \mathrm{Wm}^{-2}$ and from 95.1 to $62.7 \mathrm{Wm}^{-2}$ ) and the correlation between model and observations are increased (the average $R$ values increase from 0.76 to 0.81 and from 0.54 to 0.86 ). The evaporation fraction (EF) was also used to assess the performance of the dual-pass data assimilation scheme (Fig. 4). The EF simulations quickly dropped down and the values were lower than observations after the precipitation happened. With the assimilation of FY3A-VIRR LST, the scheme improved the underestimation of EF estimates, and improved the distribution of available energy into sensible and latent heat flux. The average BIAS values of assimilation EF results drop from -0.29 to 0.0 ; the average RMSE values drop from 0.38 to 0.12 ; the average $R$ values increase from 0.31 to 0.57 .

Furthermore, sensible heat flux measured by LAS with larger spatial representativeness was used to validate the results. The source areas of LAS measurement are calculated using a footprint model and overlaid with FY3A-VIRR pixel, which can cover more than one FY3A-VIRR pixel (Fig. 5). The sensible heat flux calculated from each covered FY3A-VIRR pixel are averaged and compared with LAS-derived sensible heat flux. The comparisons showed that the assimilation results match well against LAS
HESSD

10, 3927-3972, 2013

A dual-pass data assimilation scheme for estimating surface energy fluxes

T. R. Xu et al.

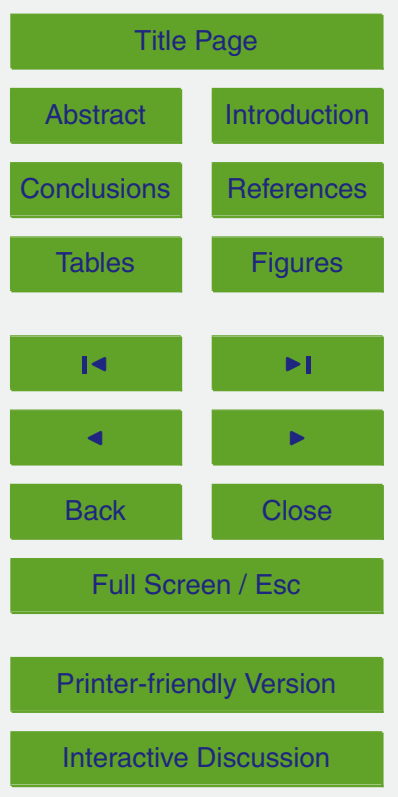


measurements, and the correlations between assimilation results and LAS measurements are higher than that of model simulations at Arou, BJ, and Guantao sites (Fig. 7).

In addition to the estimates of surface energy flux, the dual-pass data assimilation scheme also retrieved the optimized model soil moisture and vegetation parameters.

5 By comparing with in-situ measurements, the retrieved soil moisture was closer to observations than model simulation at some depth, but not all depth (Fig. 8). In pass 2 of the dual-pass data assimilation scheme, the soil moisture was fluctuated changed by assimilating FY3A-VIRR LST data. The highly nonlinear relationship between land surface temperature and soil moisture might cause the inconsistent of soil moisture 10 assimilation results and observations. Furthermore, the five vegetation parameters namely, surface roughness length $(\mathrm{zO} \mathrm{m})$, Quantum efficiency at $25^{\circ} \mathrm{C}$ (effcon), maximum rate of carboxylation at $25^{\circ} \mathrm{C}$ (vmax25), conductance-photosynthesis slope parameter (gradm), and conductance-photosynthesis intercept (binter) were retrieved at the weekly temporal scales. The retrieved parameters reached the stable values in 15 a short time, and the uncertainties were within a relatively small range (Fig. 9).

The aim of this study was to eliminate or reduce the errors between model simulation and observation. Since land surface temperature and surface energy fluxes are prognostic variables in CoLM, the simulation is very complicated and is affected by many factors. From Fig. 4, the EF simulations are increased to observations after the precipitation happened, which means soil moisture in CoLM is an important variable for surface energy flux predictions. Furthermore, the accuracy of vegetation parameters is vital for canopy transpiration. Thus, the dual-pass data assimilation is developed; pass 1 optimizes vegetation parameters at the weekly temporal scale, which is like a parameter calibration procedure; pass 2 optimizes soil moisture at the daily temporal scale; both of the two passes focus on reducing the errors of the model on weekly and daily temporal scale and correct model predictions with the assimilation of FY3A-VIRR data. The model errors in surface energy flux predictions were investigated in Sect. 5.3 of this study (Fig. 10). Figure 10 show both soil moisture and vegetation parameters caused the big model biases in surface energy flux predictions, soil moisture is the
HESSD

10, 3927-3972, 2013

A dual-pass data assimilation scheme

for estimating

surface energy fluxes

T. R. Xu et al.

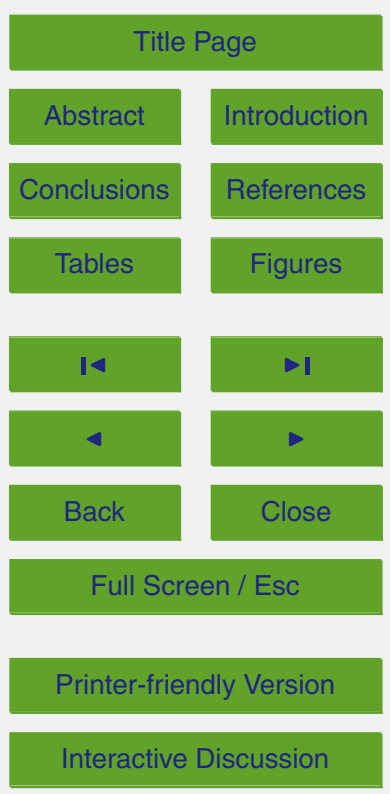


most important and vegetation parameters is the second important factors. With Pass 1 and Pass 2, the dual-pass data assimilation scheme can cut down most of the surface energy flux prediction biases (BIAS) to nearly zero. Pass 2 (optimizing soil moisture) performed better than Pass 1 (optimizing vegetation parameter). Pass 1 performed 5 better at Guantao (Cropland) and Miyun (Orchard) sites than at Arou and BJ sites (Grassland). However, a few problems still need to be resolved to enhance the effects of the data assimilation scheme. First, there are some errors between FY3A-VIRR LST and ground measurements (Fig. 2) that indicate errors in FY3A-VIRR LST retrievals and influence the data assimilation results. Thus, FY3A-VIRR land surface temperature products retrieval algorithms should be improved. Second, there is a highly nonlinear relationship between land surface temperature and soil moisture. The predictions of surface energy flux and land surface temperature can be improved by updating soil moisture, but the updated soil moisture may not fit observations well at all conditions (Fig. 8). Thus, more researches should be done to study the relationship between land surface temperature and soil moisture to improve them simultaneously. The introduction of remote sensing soil moisture data can help restricting variation of soil moisture in the data assimilation scheme. Finally, studies on developing data assimilation strategy for improving predictions of surface energy fluxes should be enhanced, including which data should be assimilated, which data assimilation algorithm should be used, which variables in land surface model should be updated, and so on.

The retrievals of model states and parameters using land surface information, especially the remote sensing data, attract much attention of researchers since they play important roles in the determination of land surface energy budget. Obviously, data assimilation is a new technique that can integrate model and observations together to produce more accurate and continuous land surface states. Since the high variability of land surface, to get more stable and reliable land surface states, multi-source observations that include in-situ measurements, airborne and satellite remote sensing data need to be assimilated into land surface models in the future.

\section{HESSD}

10, 3927-3972, 2013

A dual-pass data assimilation scheme for estimating surface energy fluxes

T. R. Xu et al.

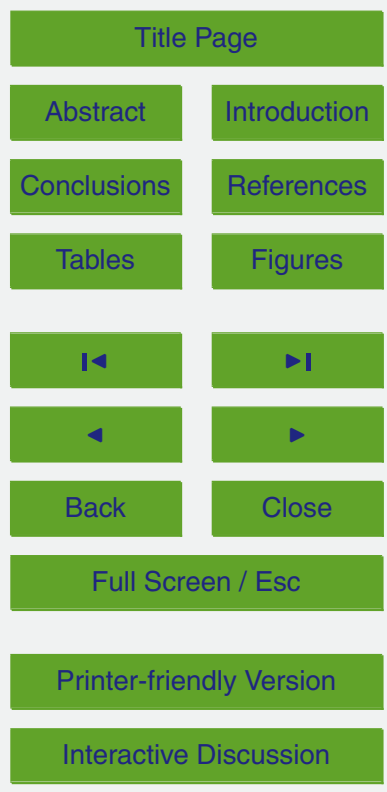


Acknowledgements. This work was funded by the National Natural Science Foundation of China (91125002 and 41201330), the Fundamental Research Funds for the Central Universities and the Special Research Foundation of the Public Benefit Industry (GYHY200706046).

\section{References}

5 Baldocchi, D., Falge, E. L., Gu, H., and Olson, R.: FLUXNET: A new tool to study the temporal and spatial variability of ecosystem-scale carbon dioxide, water vapor, and energy flux densities, B. Am. Meteorol. Soc., 82, 2415-2434, 2001.

Bastiaanssen, W. G. M., Menenti, M., Feddes, R. A., and Holtslag, A. A. M.: The surface energy balance algorithm for land (SEBAL): Part 1 Formulation, J. Hydrol., 212-213, 198-212, $10 \quad 1998$.

Bateni, S. M. and Liang, S.: Estimating surface energy fluxes using a dual-source data assimilation approach adjoined to the heat diffusion equation, J. Geophys. Res., 117, D17118, doi:10.1029/2012JD017618, 2012.

Becker, F. and Li, Z. L.: Towards a local split window method over land surface, Int. J. Remote Sens., 11, 369-393, 1990.

Boni, G., Entekhabi, D., and Castelli, F.: Land data assimilation with satellite measurements for the estimation of surface energy balance components and surface control on evaporation, Water Resour. Res., 37, 1713-1722, 2001.

Caparrini, F., Castelli, F., and Entekhabi, D.: Estimation of surface turbulent fluxes through assimilation of radiometric surface temperature sequences, J. Hydrometeorol., 5, 145-159, 2004.

Confalonieri, R., Bellocchi, G., Bregaglio, S., Donatelli, M., and Acutis, M.: Comparison of sensitivity analysis techniques: a case study with the rice model WAR M, Ecol. Model., 221, 1897-1906, 2010.

25 Crosetto, M. and Tarantola, S.: Uncertainty and sensitivity analysis: tools for GIS-based model implementation, Int. J. Geogr. Inf. Sci., 15, 415-437, 2001.

Dai, Y. J., Zeng, X. B., and Dickinson, R. E.: Common Land Model (CoLM): Technical Documentation and User's Guide, Ga. Inst. of Technol., Atlanta, 69 pp., 2001.
HESSD

10, 3927-3972, 2013

A dual-pass data assimilation scheme

for estimating

surface energy fluxes

T. R. Xu et al.

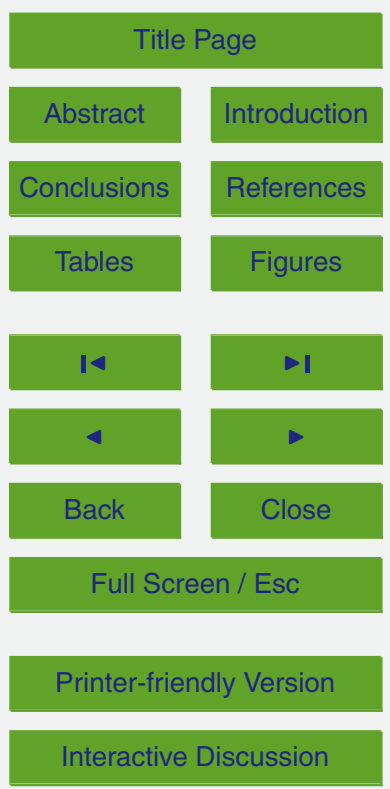


Dai, Y. J., Zeng, X. B., Dickinson, R. E., Baker, I., Bonan, G. B., Bosilovich, M. G., Dennning, A. S., Dirmeyer, P. A., Houser, P. R., Niu, G. Y., Oleson, K. W., Schlosser, C. A., and Yang, Z. L.: The common land model, B. Am. Meteorol. Soc., 84, 1013-1023, 2003.

Dai, Y. J., Dickinson, R. E., and Wang, Y. P.: A two-big-leaf model for canopy temperature, photosynthesis, and stomatal conductance, J. Climate, 17, 2281-2299, 2004.

Dickinson, R. E., Kennedy, P. J., Henderson-Sellers, A., and Wilson, M.: Biosphere-Atmosphere Transfer Scheme (BATS) version 1E as coupled to the NCAR Community Climate Model, NCAR Tech. Rep. TN-275+STR, NCAR, Boulder, Colo, 72 pp., 1986.

Dong, C. H., Yang, J., Zhang, W. J., Yang, Z. D., Lu, N. M., Shi, J. M., Zhang, P., Liu, Y. J., and Cai, B.: An overview of a new Chinese weather satellite FY-3A, B. Am. Meteorol. Soc., 90, 1531-1544, 2009.

Drouet, J. L., Capian, N., Fiorelli, J. L., Blanfort, V., Capitaine, M., Duretz, S., Gabrielle, B., Martin, R., Lardy, R., Cellier, P., and Soussana, J. F.: Sensitivity analysis for models of greenhouse gas emissions at farm level, Case study of $\mathrm{N}_{2} \mathrm{O}$ emissions simulated by the CERES-

15 EGC model, Environ. Pollut., 159, 3156-3161, 2011.

Evensen, G.: Sequential data assimilation with a nonlinear quasi-geostrophic model using monte carlo methods to forecast error statistics, J. Geophys. Res., 99, 10143-10162, 1994.

Huang, C. L., Li, X., and Lu, L.: Retrieving soil temperature profile by assimilating MODIS LST products with ensemble Kalman filter, Remote Sens. Environ., 112, 1320-1336, 2008.

Jia, Z., Liu, S., Xu, Z., Chen, Y., and Zhu, M.: Validation of remotely sensed evapotranspiration over the Hai River Basin, China, J. Geophys. Res., 117, D13113, doi:10.1029/2011JD017037, 2012.

Kalman, R. E.: A new approach to linear filtering and prediction problems, Trans. ASMEJ. Basic Eng., 82, 35-45, 1960.

Kanemasu, E. T., Verma, S. B., Smith, E. A., Fritschen, L. J., Wesely, M., Field, R. T., Kustas, W. P., Weaver, H., Stewart, J. B., Gurney, R., Panin, G., and Moncrieff, J. B.: Surface flux measurements in FIFE: An overview, J. Geophys. Res., 97, 18547-18555, doi:10.1029/92JD00254, 1992.

Kormann, R. and Meixner, F.: An analytical footprint model for non-neutral stratification, BoundLay. Meteorol., 99, 207-224, 2001.

Liang, S.: Quantitative Remote Sensing of Land Surfaces, John Wiley and Sons Inc., 534 pp., 2004.
HESSD

10, 3927-3972, 2013

A dual-pass data assimilation scheme

for estimating

surface energy fluxes

T. R. Xu et al.

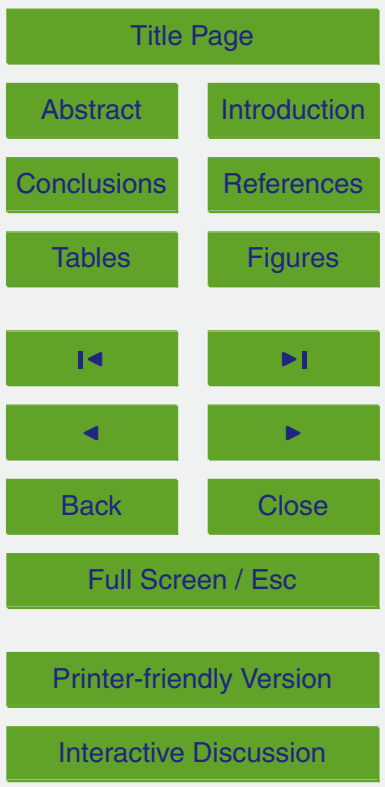


Liang, S. and Qin, J.: Data assimilation methods for land surface variable estimation, in: Advances in Land Remote Sensing: System, Modeling, Inversion and applications, edited by: Liang, S., Springer, 319-339, 2008.

Liou, Y., Galantowicz, J. F., and England, A. W.: A land surface process/radiobrightness model 5 with coupled heat and moisture transport for prairie grassland, IEEE T. Geosci. Remote, 37, 1848-1859, 1999.

Liu, S. M., Hu, G., Lu, L., and Mao, D. F.: Estimation of regional evapotranspiration by TM/ETM+ data over heterogeneous surfaces, Photogramm. Eng. Rem. S., 73, 1169-1178, 2007.

Liu, S. M., Xu, Z. W., Wang, W. Z., Jia, Z. Z., Zhu, M. J., Bai, J., and Wang, J. M.: A comparison of eddy-covariance and large aperture scintillometer measurements with respect to the energy balance closure problem, Hydrol. Earth Syst. Sci., 15, 1291-1306, doi:10.5194/hess15-1291-2011, 2011.

Liu, S. M., Xu, Z. W., Zhu, Z. L., Jia, Z. Z., and Zhu, M. J.: Measurements of evapotranspiration from eddy-covariance systems and large aperture scintillometers in the Hai River Basin,

Margulis, S. A., McLaughlin, D., Entekhabi, D., and Dunne, S.: Land data assimilation and estimation of soil moisture using measurements from the Southern Great Plains 1997 Field Experiment, Water Resour. Res., 38, 1229, doi:10.1029/2001WR001114, 2002.

Miao, Z., Lathrop, R. G., Xu, M., La Puma, I. P., Clark, K. L., Hom, J., Skowronski, N., and Van 20 Tuyl, S.: Simulation and sensitivity analysis of carbon storage and fluxes in the New Jersey Pinelands, Environ. Modell. Softw., 26, 1112-1122, 2011.

Moradkhani, H., Sorooshian, S., Gupta, H. V., and Houser, P. R.: Dual state-parameter estimation of hydrological models using ensemble Kalman filter, Adv. Water Resour., 28, 135-147, 2005.

Pipunic R. C., Walker, J. P., and Western, A.: Assimilation of remotely sensed data for improved latent and sensible heat flux prediction: a comparative synthetic study, Remote Sens. Environ., 112, 1295-1305, 2008.

Qin, J., Liang, S., Yang, K., Koike, T., Liu, R., and Kaihotsu, I.: Simultaneous estimation of both soil moisture and model parameters using particle filtering method through the assimilation 30 of microwave signal, J. Geophys. Res., 114, D15103, doi:10.1029/2008JD011358, 2009.

Reusser, D. E., Buytaert, W., and Zehe, E.: Temporal dynamics of model parameter sensitivity for computationally expensive models with the Fourier amplitude sensitivity test, Water Resour. Res., 47, W07551, doi:10.1029/2010WR009947, 2011.

\section{HESSD}

10, 3927-3972, 2013

A dual-pass data assimilation scheme

for estimating

surface energy fluxes

T. R. Xu et al.

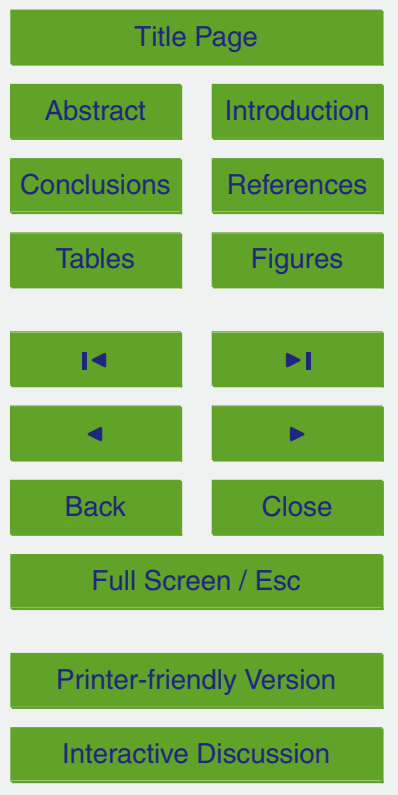


Rodriguez-Camino, E. and Avissar, R.: Comparison of three land-surface schemes with the Fourier amplitude sensitivity test (FAST), Tellus A, 50, 313-332, 1998.

Saltelli, A. and Bolado, R.: An alternative way to compute Fourier amplitude sensitivity test (FAST), Comput. Stat. Data An., 26, 445-460, 1999.

5 Saltelli, A., Chan, K., and Scott, E. M.: Sensitivity Analysis, John Wiley \& Sons, LTD, Chichester, New York, 2000.

Schuurmans, J. M., Troch, P. A., Veldhuizen, A. A., Bastiaanssen, W. G. M., and Bierkens, M. F. P.: Assimilation of remotely sensed latent heat flux in a distributed hydrological model, Adv. Water Resour., 26, 151-159, 2003.

10 Schuurmans, J. M., van Geer, F. C., and Bierkens, M. F. P.: Remotely sensed latent heat fluxes for model error diagnosis: a case study, Hydrol. Earth Syst. Sci., 15, 759-769, doi:10.5194/hess-15-759-2011, 2011.

Sellers, P. J., Randall, D. A., Collatz, G. J., Field, C. B., Dazlich, D. A., Zhang, C., Collelo, G. D., and Bounoua, L.: A revised land surface parameterization ( $\mathrm{SiB} 2$ ) for atmosphere GCMs, Part I: Model formulation, J. Climate, 9, 676-705, 1996.

Shangguan, W., Dai, Y., Liu, B., Ye, A., and Yuan, H.: A soil particle-size distribution dataset for regional land and climate modelling in China, Geoderma, 171-172, 85-91, 2012.

Sobol, I. M.: Sensitivity estimates for nonlinear mathemetical models, Math. Model. Comput. Exp., 1, 407-414, 1993.

20 Su, Z.: The Surface Energy Balance System (SEBS) for estimation of turbulent heat fluxes, Hydrol. Earth Syst. Sci., 6, 85-100, doi:10.5194/hess-6-85-2002, 2002.

Tian, X., Xie, Z., Dai, A., Shi, C., Jia, B., Chen, F., and Yang, K.: A dual-pass variational data assimilation framework for estimating soil moisture profiles from AMSR-E microwave brightness temperature, J. Geophys. Res., 114, D16102, doi:10.1029/2008JD011600, 2009.

Wang, W. H., Liang, S. L., and Tilden, M.: Validating MODIS land surface temperature products using long-term nighttime ground measurements, Remote Sens. Environ., 112, 623-635, 2008.

Xiao, Z. Q., Liang, S., Wang, J. D., Jiang, B., Li, X. J.: Real-time retrieval of leaf area index from MODIS time series data, Remote Sens. Environ., 115, 97-106, 2011.

so Xu, T., Liu, S. M., Liang, S., and Qin, J.: Improving predictions of water and heat fluxes by assimilating MODIS land surface temperature products into common land model, J. Hydrometeorol., 12, 227-244, 2011.

A dual-pass data assimilation scheme for estimating surface energy fluxes

T. R. Xu et al.

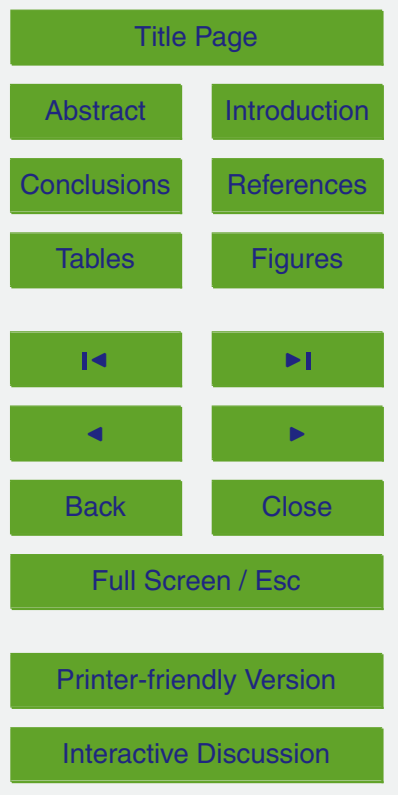


Yang, $\mathrm{H}$. and Yang, Z. D.: A modified land surface temperature split window retrieval algorithm and its applications over China, Global Planet. Change, 52, 207-215, 2006.

Yang, J. and Dong, C. H.: Operational products and application for the new generation of polarorbiting FY meteorological satellites, Science Press, Beijing, 214-218, 2011.

5 Yang, K. and Wang, J. M.: A temperature prediction-correction method for estimating surface soil heat flux from soil temperature and moisture data, Sci. China Ser. D, 51, 721-729, 2008.

Yang, K., Takahiro, W., and Toshio, K.: An auto-calibration system to assimilate AMSR-E data into a land surface model for estimating soil moisture and surface energy budge, J. Meteorol. Soc. Jpn., 85, 229-242, 2007.

\section{HESSD}

10, 3927-3972, 2013

A dual-pass data assimilation scheme

for estimating

surface energy fluxes

T. R. Xu et al.

Title Page

Abstract

Introduction

Conclusions

References

Tables

Figures

14

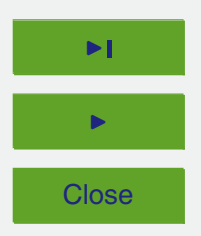

Back

Printer-friendly Version

Interactive Discussion 
Table 1. Summary of equipments and surface characteristics at the four experiment sites.

\begin{tabular}{|c|c|c|c|c|c|}
\hline Instrument & Variable & $\begin{array}{l}\text { Arou } \\
\text { Height/Depth (m) }\end{array}$ & $\begin{array}{l}\text { BJ } \\
\text { Height/Depth (m) }\end{array}$ & $\begin{array}{l}\text { Guantao } \\
\text { Height/Depth (m) }\end{array}$ & $\begin{array}{l}\text { Miyun } \\
\text { Height/Depth (m) }\end{array}$ \\
\hline EC & $\begin{array}{l}\text { Sensible and La- } \\
\text { tent heat Flux }\end{array}$ & 3.15 & 3.0 & 15.6 & 26.66 \\
\hline LAS & Sensible heat flux & $\begin{array}{l}9.5 \\
\text { (path length } 2390 \mathrm{~m} \text { ) }\end{array}$ & $\begin{array}{l}8.6 \\
\text { (path length } 1560 \mathrm{~m} \text { ) }\end{array}$ & $\begin{array}{l}15.6 \\
\text { (path length } 2760 \mathrm{~m} \text { ) }\end{array}$ & $\begin{array}{l}35.86 \\
\text { (path length } 2420 \mathrm{~m} \text { ) }\end{array}$ \\
\hline \multirow[t]{5}{*}{ AWS } & $\begin{array}{l}\text { Air temperature/ } \\
\text { Humidity }\end{array}$ & 2.0 and 10.0 & 8.2 and 10.0 & 4 and 12.5 & 10.66 and 30.56 \\
\hline & Radiation & 1.5 & 1.5 & 15.7 & 30.76 \\
\hline & Soil heat flux & 0.05 & - & 0.02 & 0.02 \\
\hline & Soil temperature & $\begin{array}{l}0.1,0.2,0.4,0.8,1.2 \\
1.6\end{array}$ & $0,0.04,0.1,0.2,0.4$ & $\begin{array}{l}0, \quad 0.02, \quad 0.05, \quad 0.1 \\
0.2,0.4,0.6,0.8,1\end{array}$ & $\begin{array}{l}0,0.02,0.05, \quad 0.1, \\
0.2,0.4,0.6,0.8,1\end{array}$ \\
\hline & Soil moisture & $\begin{array}{l}0.1,0.2,0.4,0.8,1.2 \\
1.6\end{array}$ & $0.04,0.2$ & $\begin{array}{l}0.02,0.05,0.1 \\
0.2,0.4,0.6,1\end{array}$ & $\begin{array}{l}0.02,0.05,0.1 \\
0.2,0.4,0.6,1\end{array}$ \\
\hline Elevation (m) & & 2990 & 4520 & 30 & 350 \\
\hline Landscape & & Alpine meadow & Grass & Crop & Orchard \\
\hline
\end{tabular}

A dual-pass data assimilation scheme

for estimating surface energy fluxes

T. R. Xu et al.

Title Page

Abstract Introduction

Conclusions

References

Tables

Figures

14

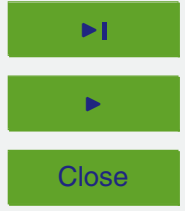

Back

Full Screen / Esc

Printer-friendly Version

Interactive Discussion 


\section{HESSD}

10, 3927-3972, 2013

\section{A dual-pass data assimilation scheme \\ for estimating \\ surface energy fluxes}

Table 2. Some soil and vegetation parameters in common land model (CoLM).

\begin{tabular}{llll}
\hline Parameter & Description & unit & Range \\
\hline zOm & Surface roughness length & $\mathrm{m}$ & $0.05-0.21$ \\
displa & Zero plane displacement & $\mathrm{m}$ & $0.33-2.0$ \\
effcon & Quantum efficiency at $25^{\circ} \mathrm{C}$ & $\mu \mathrm{mol} \mathrm{mol}^{-1}$ & $0.04-0.08$ \\
vmax 25 & Maximum rate of carboxylation at $25^{\circ} \mathrm{C}$ & $\mu \mathrm{mol} \mathrm{m}^{-2} \mathrm{~s}^{-1}$ & $10.0-200.0$ \\
hlti & photosynthetic stress low temperature & $\mathrm{K}$ & $278.0-288.0$ \\
hhti & photosynthetic stress high temperature & $\mathrm{K}$ & $303.0-313.0$ \\
gradm & conductance-photosynthesis slope parameter & - & $4.0-9.0$ \\
binter & conductance-photosynthesis intercept & - & $0.01-0.04$ \\
ra & coefficient of root profile & - & $0.0-15.0$ \\
rb & coefficient of root profile & - & $0.0-3.0$ \\
\hline
\end{tabular}

T. R. Xu et al.

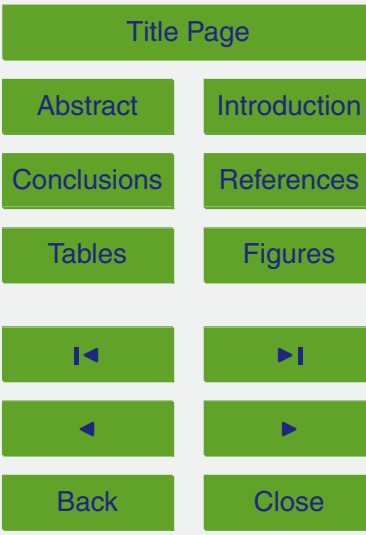

Full Screen / Esc

Printer-friendly Version

Interactive Discussion 
Table 3. First order and total sensitivity indices of model parameters*.

\begin{tabular}{llllllll}
\hline Parameter & \multicolumn{1}{c}{$H$} & \multicolumn{2}{c}{$L E$} & \multicolumn{2}{c}{$T s$} \\
& $S_{i}$ & $S_{\mathrm{Ti}}$ & $S_{i}$ & $S_{\mathrm{Ti}}$ & $S_{i}$ & $S_{\mathrm{Ti}}$ \\
\hline z0m & $9.44 \mathrm{E}-2$ & 0.19 & $5.53 \mathrm{E}-3$ & 0.08 & $2.33 \mathrm{E}-1$ & 0.34 \\
displa & $1.76 \mathrm{E}-3$ & 0.07 & $1.87 \mathrm{E}-3$ & 0.07 & $2.23 \mathrm{E}-3$ & 0.06 \\
effcon & $1.56 \mathrm{E}-1$ & 0.33 & $1.41 \mathrm{E}-1$ & 0.32 & $1.21 \mathrm{E}-1$ & 0.27 \\
vmax25 & $1.11 \mathrm{E}-1$ & 0.27 & $1.21 \mathrm{E}-1$ & 0.28 & $1.18 \mathrm{E}-1$ & 0.26 \\
hlti & $6.09 \mathrm{E}-4$ & 0.03 & $6.92 \mathrm{E}-4$ & 0.04 & $9.22 \mathrm{E}-4$ & 0.04 \\
hhti & $1.12 \mathrm{E}-2$ & 0.09 & $1.15 \mathrm{E}-2$ & 0.08 & $1.28 \mathrm{E}-2$ & 0.08 \\
gradm & $1.85 \mathrm{E}-2$ & 0.13 & $1.63 \mathrm{E}-2$ & 0.12 & $1.55 \mathrm{E}-2$ & 0.12 \\
binter & $5.20 \mathrm{E}-2$ & 0.17 & $5.79 \mathrm{E}-2$ & 0.18 & $5.49 \mathrm{E}-2$ & 0.17 \\
ra & $1.47 \mathrm{E}-2$ & 0.07 & $1.86 \mathrm{E}-2$ & 0.09 & $1.36 \mathrm{E}-2$ & 0.09 \\
rb & $3.53 \mathrm{E}-2$ & 0.14 & $3.27 \mathrm{E}-2$ & 0.12 & $2.13 \mathrm{E}-2$ & 0.10 \\
\hline
\end{tabular}

HESSD

10, 3927-3972, 2013

A dual-pass data assimilation scheme

for estimating

surface energy fluxes

T. R. Xu et al.

Title Page

Abstract

Introduction

Conclusions

References

Tables

Figures

* Here $H, L E$, and Ts mean sensible heat flux, latent heat flux and land surface temperature; this table averaged the sensitivity analysis results of the four experiment sites.

14

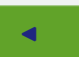

Back

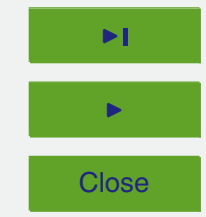

Full Screen / Esc

Printer-friendly Version

Interactive Discussion 
Table 4. BIAS, RMSE and $R$ values of simulation and assimilation results compared with halfhourly EC-derived sensible and latent heat fluxes*.

\begin{tabular}{llrrllrrrr}
\hline & & \multicolumn{2}{c}{ Ts $(\mathrm{K})$} & \multicolumn{2}{c}{$H\left(\mathrm{Wm}^{-2}\right)$} & \multicolumn{2}{c}{$L E\left(\mathrm{Wm}^{-2}\right)$} & \multicolumn{2}{c}{$\mathrm{EF}(-)$} \\
\hline Site & Statistics & Sim & Ass & Sim & Ass & Sim & Ass & Sim & Ass \\
\hline Arou & BIAS & 2.8 & 0.4 & 54.6 & 11.2 & -46.2 & 20.9 & -0.39 & -0.03 \\
& RMSE & 5.5 & 2.8 & 97.9 & 36.5 & 116.8 & 53.9 & 0.47 & 0.10 \\
& $R$ & 0.84 & 0.94 & 0.75 & 0.84 & 0.53 & 0.93 & 0.25 & 0.50 \\
\hline BJ & BIAS & -0.6 & -2.4 & 45.0 & 14.8 & -22.6 & 22.6 & -0.29 & -0.01 \\
& RMSE & 3.4 & 4.2 & 80.2 & 48.9 & 97.4 & 76.0 & 0.35 & 0.16 \\
& $R$ & 0.96 & 0.96 & 0.89 & 0.89 & 0.45 & 0.73 & 0.23 & 0.30 \\
\hline Guantao & BIAS & 2.2 & 0.3 & 31.8 & 4.0 & -33.1 & 15.1 & -0.33 & 0.00 \\
& RMSE & 4.1 & 2.0 & 64.6 & 27.8 & 90.9 & 52.5 & 0.46 & 0.12 \\
& $R$ & 0.71 & 0.95 & 0.70 & 0.86 & 0.39 & 0.90 & 0.28 & 0.71 \\
\hline Miyun & BIAS & 0.8 & 0.1 & 19.6 & 0.8 & -8.3 & 16.5 & -0.16 & 0.03 \\
& RMSE & 2.7 & 2.5 & 56.2 & 43.3 & 75.3 & 68.4 & 0.25 & 0.11 \\
& $R$ & 0.92 & 0.95 & 0.70 & 0.68 & 0.77 & 0.86 & 0.46 & 0.76 \\
\hline Average & BIAS & 1.3 & -0.4 & 37.8 & 7.7 & -27.6 & 18.8 & -0.29 & 0.00 \\
& RMSE & 3.9 & 2.9 & 74.7 & 39.1 & 95.1 & 62.7 & 0.38 & 0.12 \\
& $R$ & 0.86 & 0.95 & 0.76 & 0.81 & 0.54 & 0.86 & 0.31 & 0.57 \\
\hline
\end{tabular}

${ }^{*}$ Here BIAS, RMSE and $R$ means the bias, root mean square error and correlation between the model results and observations; $H, L E, E F$, and Ts mean sensible and latent heat flux $\left(\mathrm{Wm}^{-2}\right)$,

evapotranspiration fraction (-) and land surface temperature $(\mathrm{K})$; Sim means model simulation results; Ass means data assimilation results with dual-pass data assimilation scheme.
HESSD

10, 3927-3972, 2013

A dual-pass data assimilation scheme

for estimating

surface energy fluxes

T. R. Xu et al.

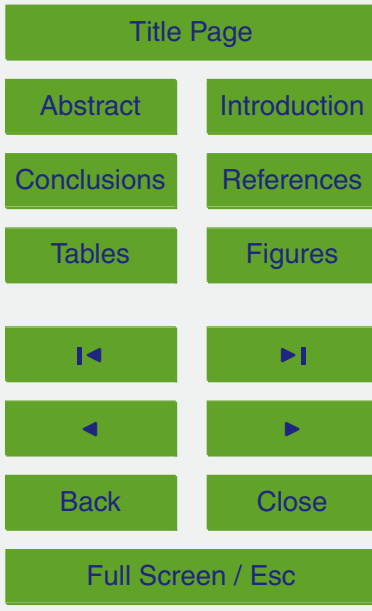

Printer-friendly Version

Interactive Discussion 


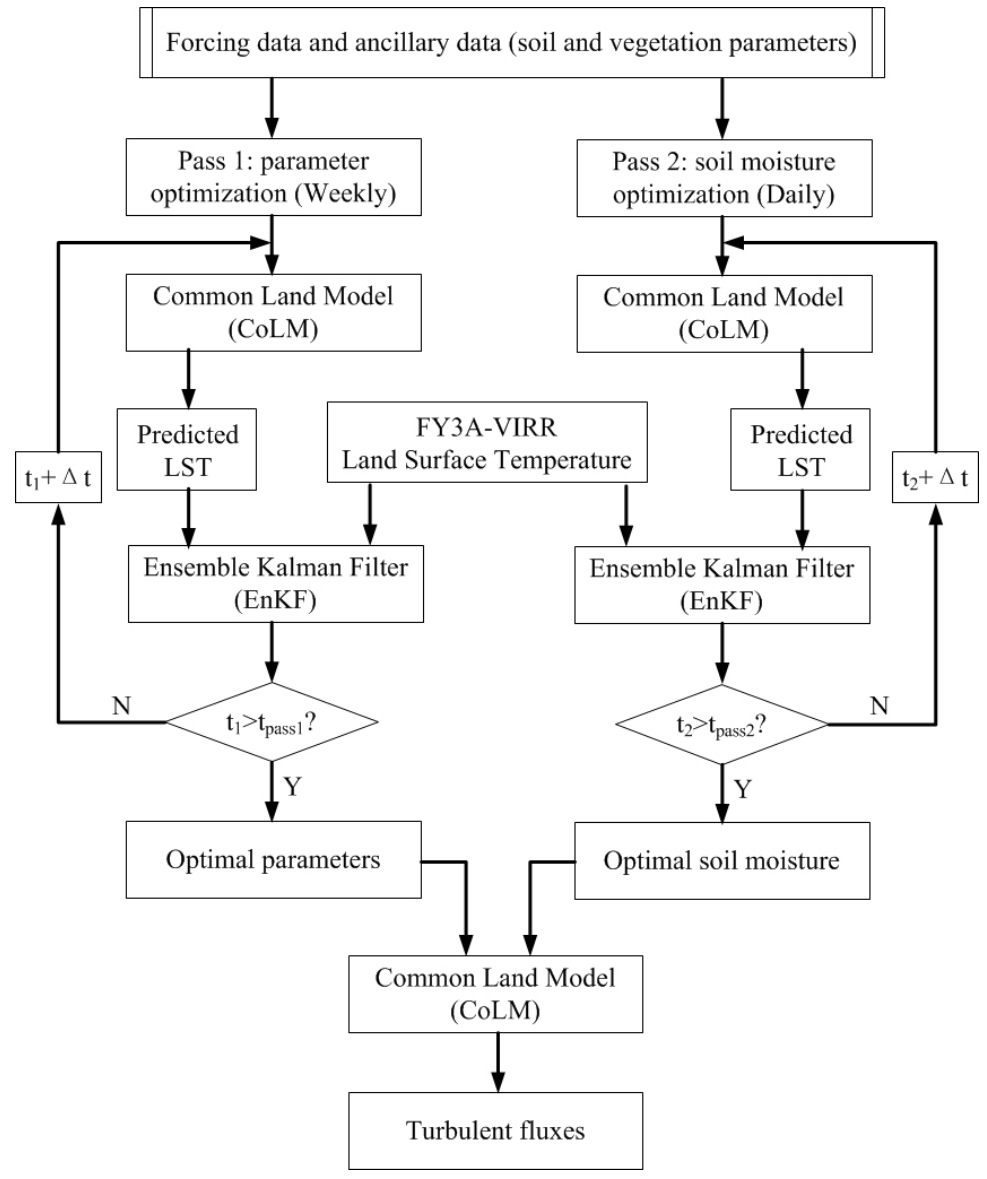

HESSD

10, 3927-3972, 2013

A dual-pass data assimilation scheme

for estimating surface energy fluxes

T. R. Xu et al.

\section{Title Page}

\section{Full Screen / Esc}

Printer-friendly Version

Fig. 1. The flowchart of dual-pass data assimilation scheme.

Interactive Discussion 

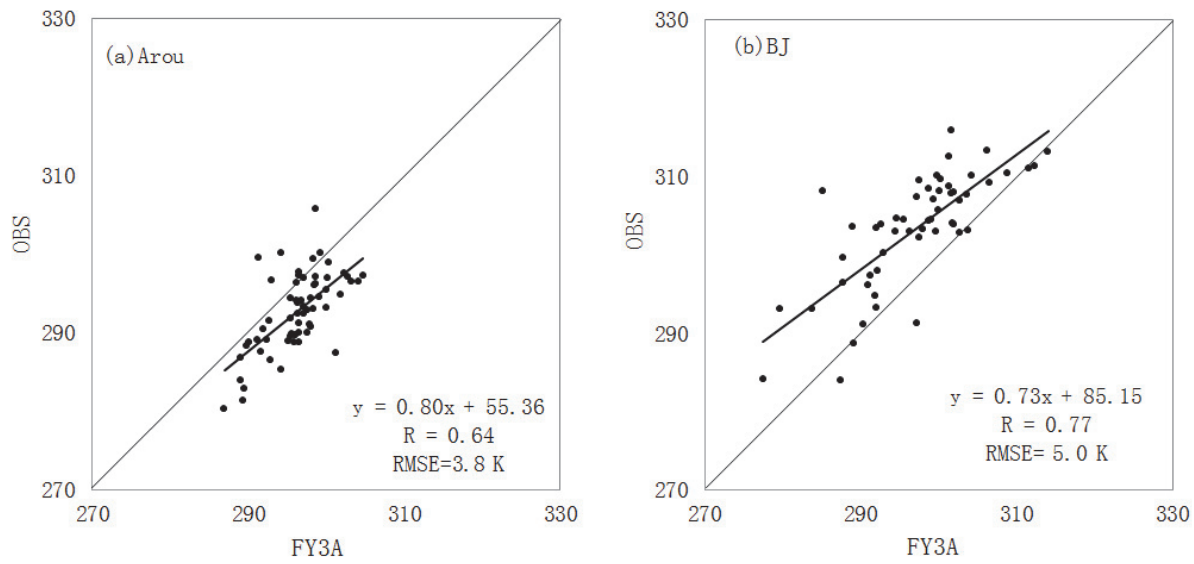

\section{HESSD}

10, 3927-3972, 2013

A dual-pass data assimilation scheme

for estimating surface energy fluxes

T. R. Xu et al.
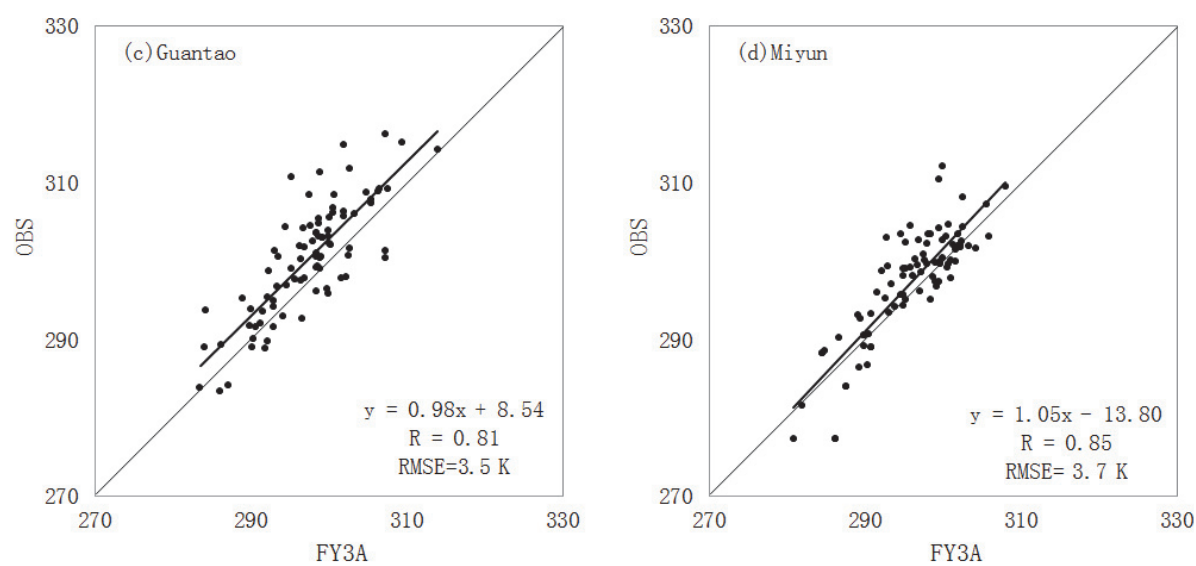

Title Page

Abstract Introduction

Conclusions

References

Tables

Figures

14

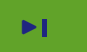

4

Back

Close

Full Screen / Esc

Printer-friendly Version

Fig. 2. Comparisons between the FY3A-VIRR LST data and ground-measured surface temperatures (OBS) at the four experiment sites. 


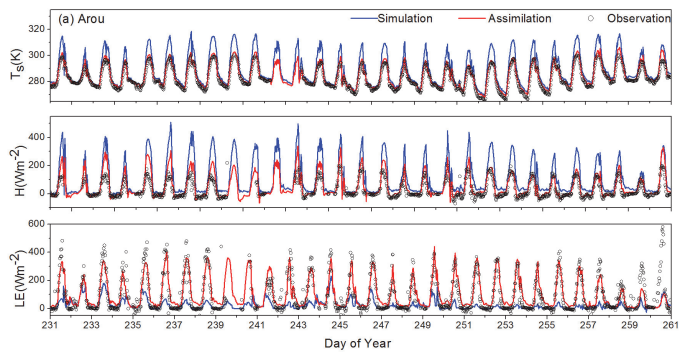

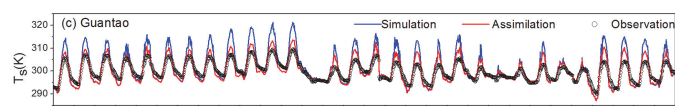

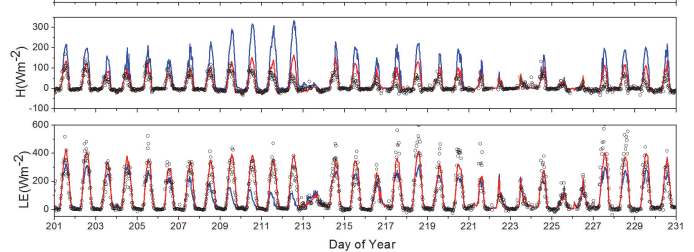

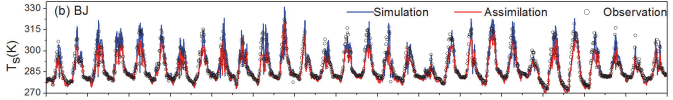

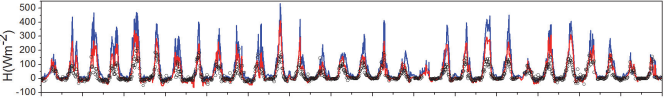

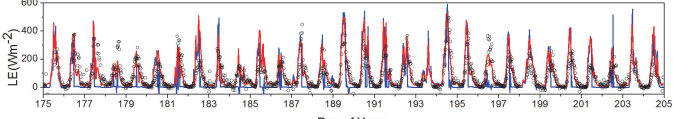

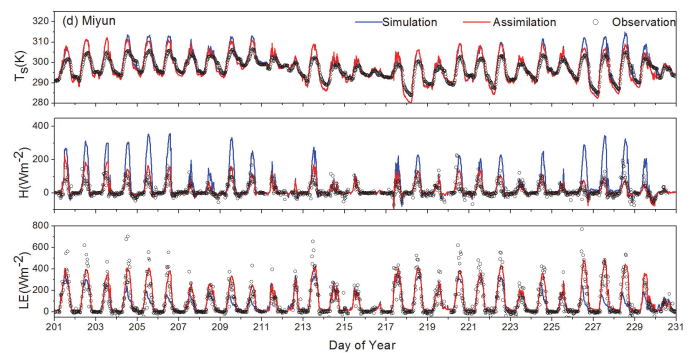

Fig. 3. Comparisons of EC-derived sensible and latent heat fluxes with estimates from simulation and assimilation at the four experiment sites.
A dual-pass data assimilation scheme for estimating surface energy fluxes

T. R. Xu et al.

\section{Title Page}

Abstract Introduction

Conclusions References

14

$\rightarrow$

4

Back

Close

\section{Full Screen / Esc}

Printer-friendly Version

Interactive Discussion 


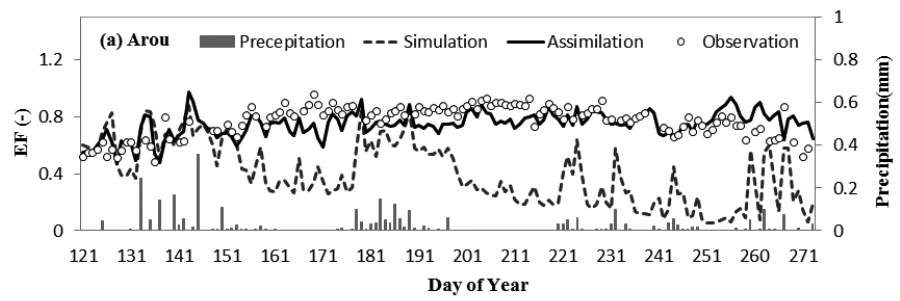

HESSD

10, 3927-3972, 2013

A dual-pass data assimilation scheme

for estimating

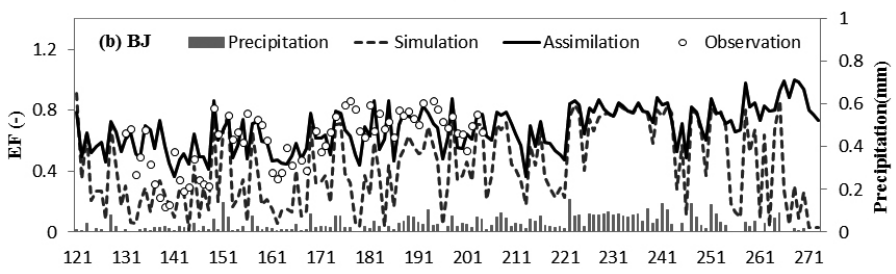
Day of Year

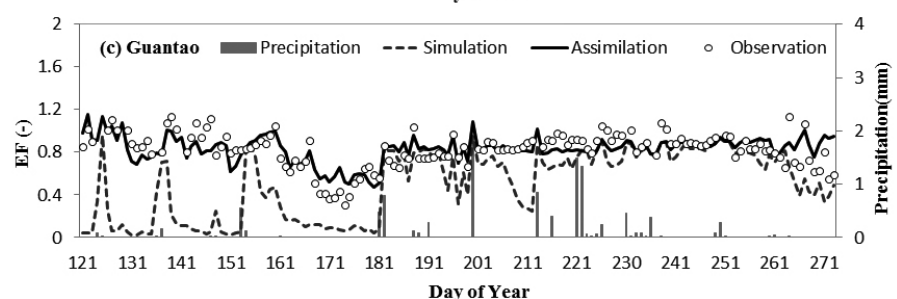

Title Page

Abstract Introduction

T. R. Xu et al.

Conclusions

References

Tables

Figures

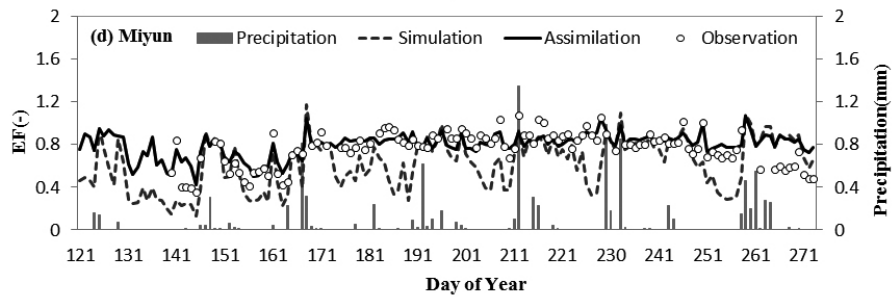

14

4

Back

Close

\section{Full Screen / Esc}

Printer-friendly Version

Fig. 4. Comparisons of EC-derived evaporation fraction (EF) with estimates from simulation and assimilation at the four experiment sites from day of year 121 to $273,2010$. 

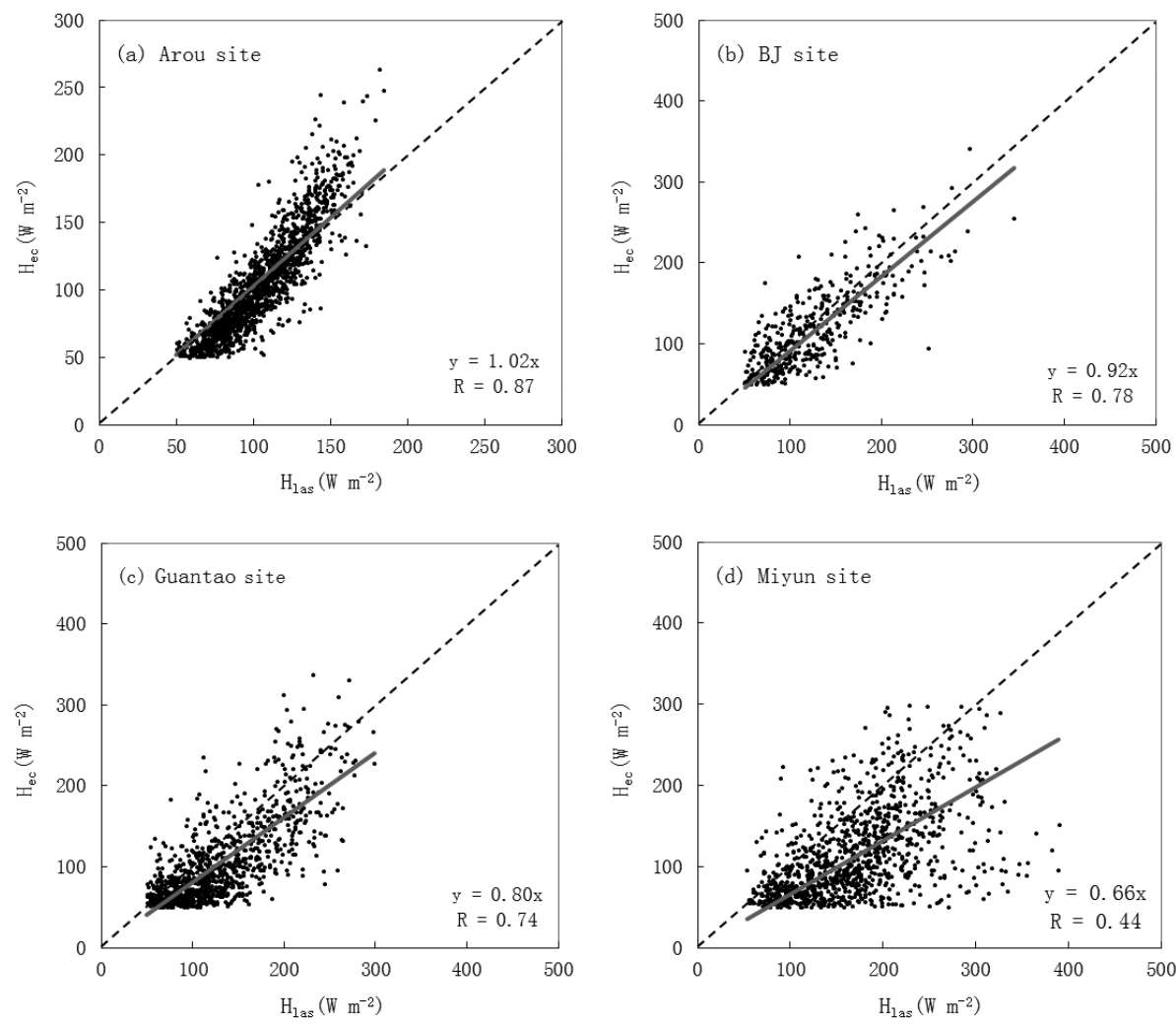

\section{HESSD}

10, 3927-3972, 2013

A dual-pass data assimilation scheme

for estimating surface energy fluxes

T. R. Xu et al.

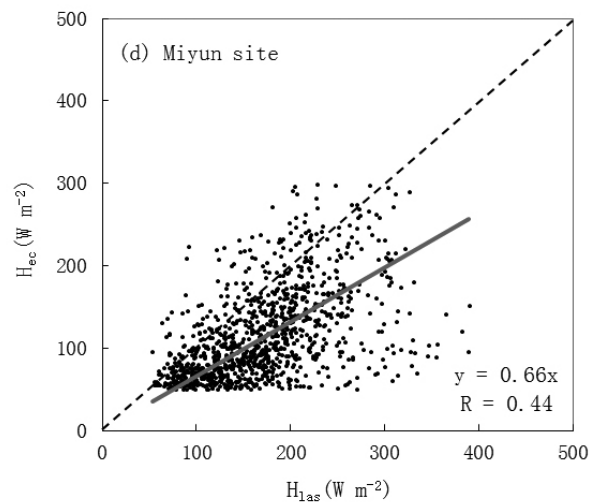

Fig. 5. Comparisons of sensible heat flux derived from LAS $\left(H_{\mathrm{LAS}}\right)$ and EC $\left(H_{\mathrm{EC}}\right)$ when $H_{\mathrm{LAS}}$ and $H_{\mathrm{EC}}>50 \mathrm{Wm}^{-2}$ at the four experiment sites from day of year 121 to $273,2010$.

\section{Title Page}

Abstract

Introduction

Conclusions

References

Tables

Figures

14

4

Back

\section{Full Screen / Esc}

Printer-friendly Version

Interactive Discussion 


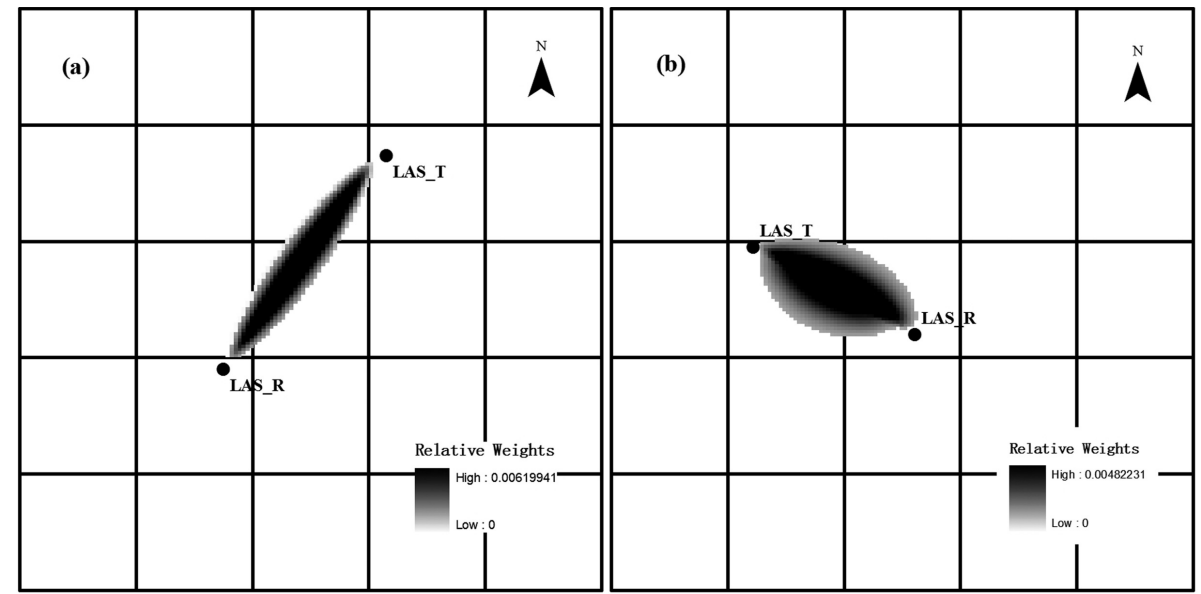

\section{HESSD}

10, 3927-3972, 2013

A dual-pass data assimilation scheme

for estimating surface energy fluxes

T. R. Xu et al.

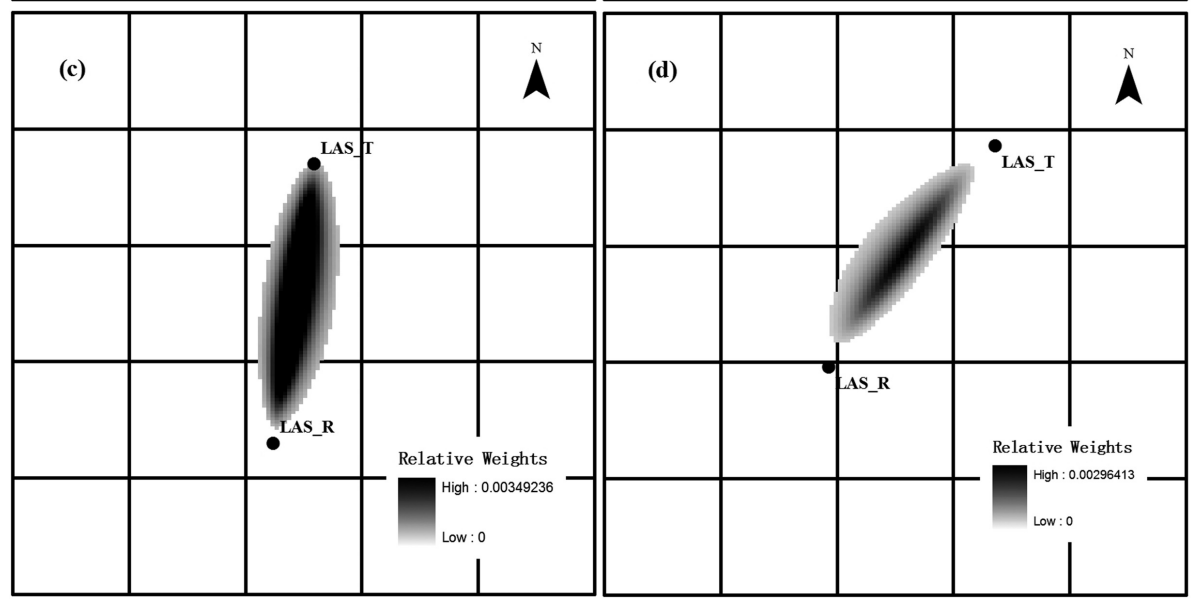

Title Page

\section{Full Screen / Esc}

Printer-friendly Version

Fig. 6. The monthly source areas of LAS measurements overlaid with FY3A-VIRR pixels at the four experiment sites - (a) Arou site; (b) BJ site; (c) Guantao site; (d) Miyun site. 

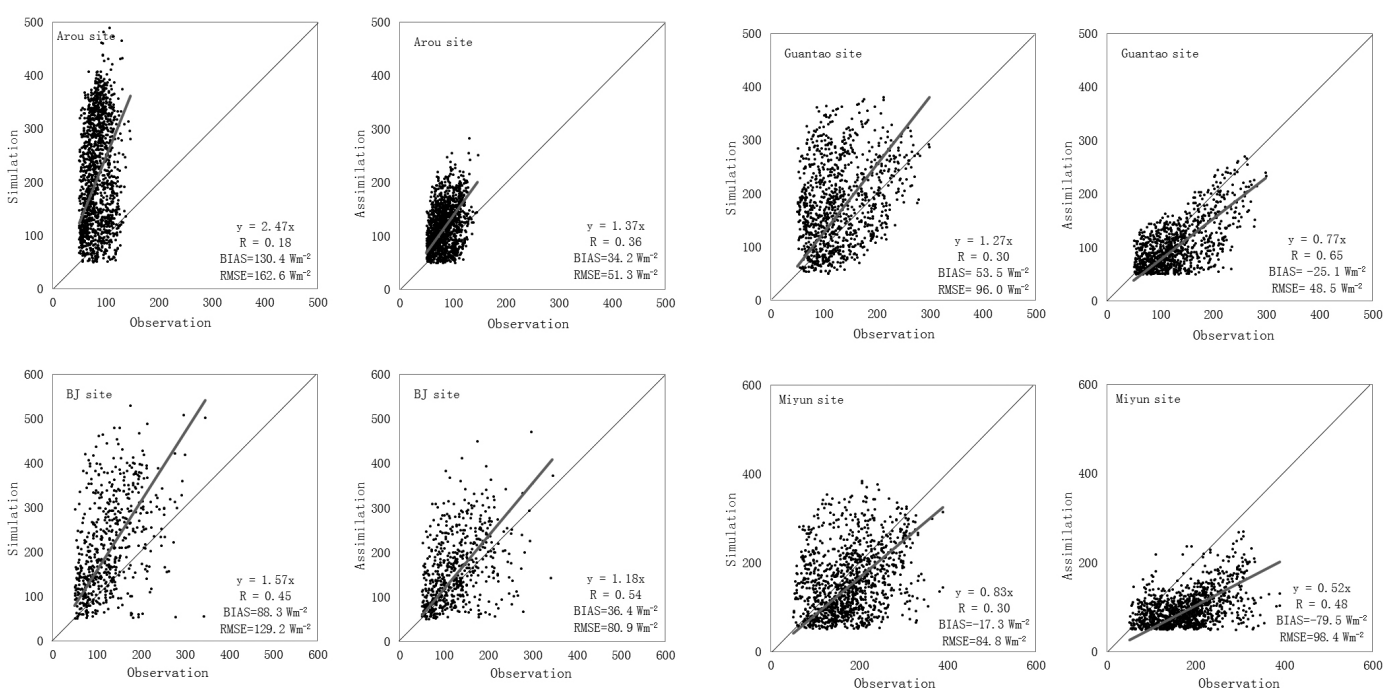

Fig. 7. Comparisons of LAS-derived sensible heat flux with estimates from simulation and assimilation when $H_{\text {LAS }}>50 \mathrm{Wm}^{-2}$ at the four experiment sites from day of year 121 to 273 , 2010.

\section{HESSD}

10, 3927-3972, 2013

A dual-pass data assimilation scheme

for estimating surface energy fluxes

T. R. Xu et al.

\section{Title Page}

Abstract Introduction

Conclusions

References

Tables

Figures

14

$\rightarrow 1$

$\triangleleft$

Back

Close

\section{Full Screen / Esc}

Printer-friendly Version

Interactive Discussion 


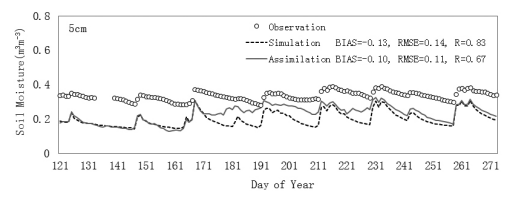

HESSD

10, 3927-3972, 2013
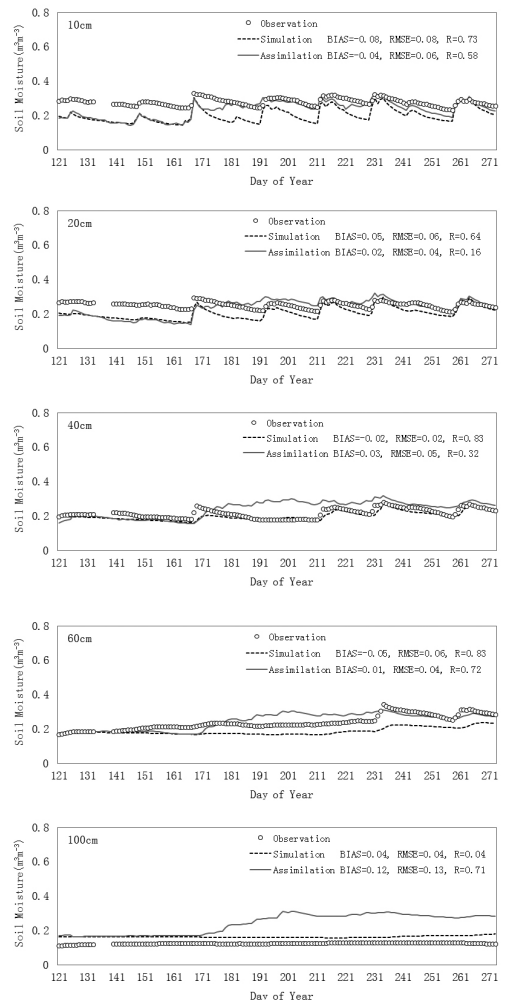

Fig. 8. Comparisons of soil moisture measurements with estimates from simulation and assimilation at Miyun site from day of year 121 to 273, 2010.

A dual-pass data assimilation scheme

for estimating surface energy fluxes

T. R. Xu et al.

Title Page

Abstract Introduction

Conclusions

References

Tables

Figures

14

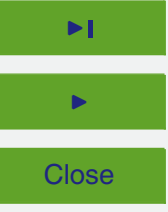

Back

Full Screen / Esc

Printer-friendly Version

Interactive Discussion 

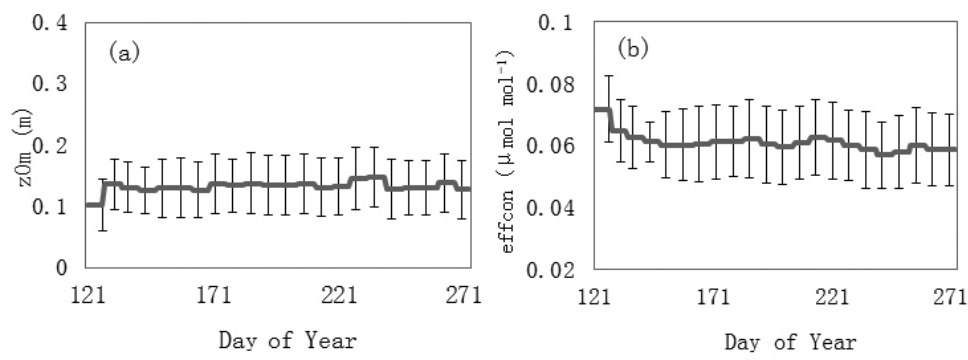

HESSD

10, 3927-3972, 2013

A dual-pass data assimilation scheme

for estimating surface energy fluxes

T. R. Xu et al.
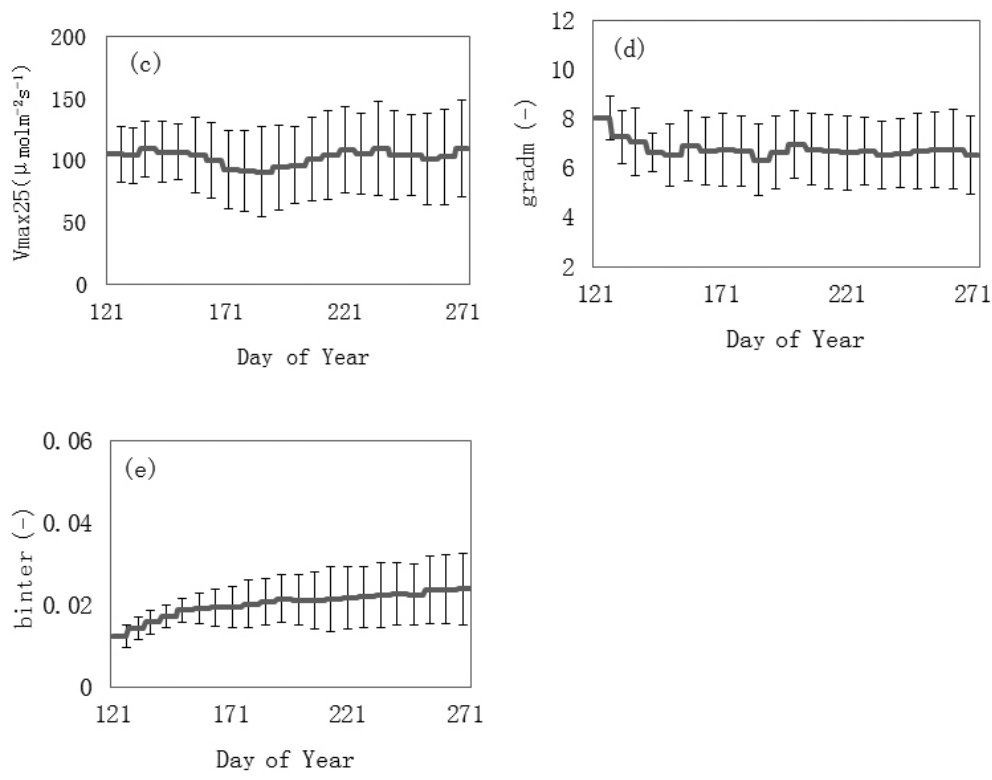

Fig. 9. Model parameter retrievals at Miyun site from day of year 121 to 273,2010 (the error bars means the uncertainty of the retrieved parameter).

Title Page

Abstract Introduction

Conclusions

References

Tables

Figures

14

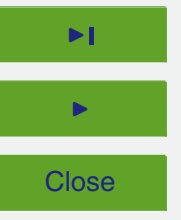

Back

Full Screen / Esc

Printer-friendly Version

Interactive Discussion 

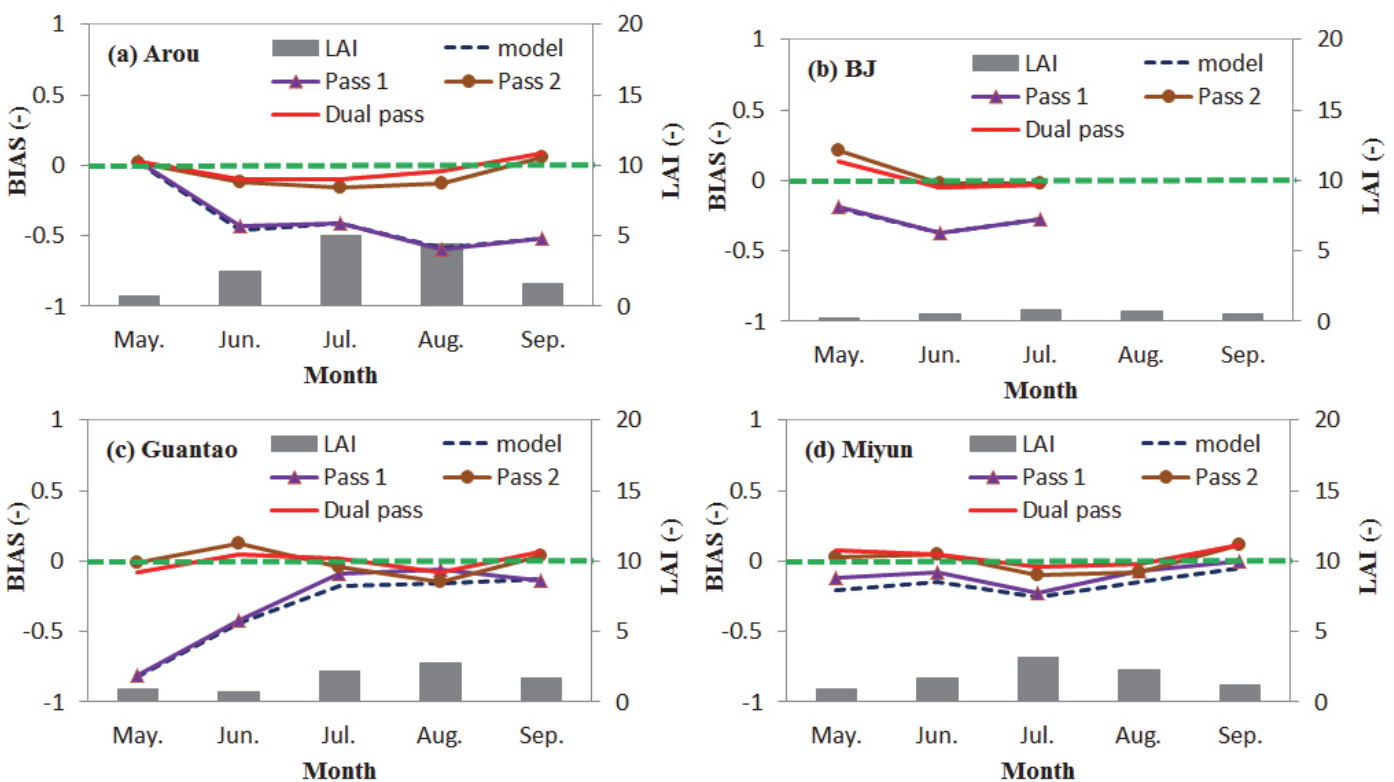

Fig. 10. Evaporation fraction (EF) biases (BIAS) at the experiment sites from May to September 2010 - (a) Arou site; (b) BJ site; (c) Guantao site; (d) Miyun site.

\section{HESSD}

10, 3927-3972, 2013

A dual-pass data assimilation scheme

for estimating surface energy fluxes

T. R. Xu et al.

\section{Title Page}

Abstract Introduction

Conclusions References

Tables Figures

14 I

4

Back

Close

\section{Full Screen / Esc}

Printer-friendly Version

Interactive Discussion 